UNIVERSIDADE DE SÃO PAULO

INSTITUTO DE PSICOLOGIA

PROGRAMA DE PÓS-GRADUAÇÃO EM PSICOLOGIA EXPERIMENTAL

Efeito de diferentes contingências de reforço no estabelecimento de discriminações condicionais e na formação de classes de estímulos equivalentes

São Paulo

2014 
PAULO SÉRGIO DILLON SOARES FILHO

Efeito de diferentes contingências de reforço no estabelecimento de discriminações condicionais e na formação de classes de estímulos equivalentes

(Versão Corrigida)

São Paulo 
Efeito de diferentes contingências de reforço no estabelecimento de discriminações condicionais e na formação de classes de estímulos equivalentes

\section{(Versão Corrigida)}

Tese apresentada ao Departamento de Psicologia Experimental (PSE) da Universidade de São Paulo USP como requisito para a obtenção do título de Doutor

Orientador: Prof. Dr. Gerson Yukio Tomanari.

Coorientador: Prof. Dr. Romariz da Silva Barros (UFPA)

São Paulo 


\section{Catalogação na publicação}

Biblioteca Dante Moreira Leite

Instituto de Psicologia da Universidade de São Paulo

Soares Filho, Paulo Sérgio Dillon.

Efeito de diferentes contingências de reforço no estabelecimento de discriminações condicionais e na formação de classes de estímulos equivalentes / Paulo Sérgio Dillon Soares Filho; orientador Gerson Yukio Tomanari. -- São Paulo, 2014.

$94 \mathrm{f}$.

Tese (Doutorado - Programa de Pós-Graduação em Psicologia. Área de Concentração: Psicologia Experimental) - Instituto de Psicologia da Universidade de São Paulo.

1. Contingências de reforço 2. Discriminação condicional 3. Equivalência de estímulos I. Título.

BF319.5.R4 
Nome: Paulo Sérgio Dillon Soares Filho

Título: Efeito de diferentes contingências de reforço no estabelecimento de discriminações condicionais e na formação de classes de estímulos equivalentes

Tese apresentada ao Departamento de Psicologia Experimental (PSE) da Universidade de São Paulo (USP) como requisito para a obtenção do título de Doutor

Aprovado em:

Banca Examinadora

Prof. Dr.

Instituição:

Assinatura:

Prof. Dr.

Instituição:

Assinatura:

Prof. Dr.

Instituição:

Assinatura:

Prof. Dr.

Instituição:

Assinatura:

Prof. Dr.

Instituição:

Assinatura: 


\section{AGRADECIMENTOS}

Primeiramente, gostaria de agradecer à minha mãe Rosângela Cecim Albim e avós: Rossicler, Milza e Carmem (Carmita) pela formação e apoio incondicional, sem os quais a conclusão de mais esta etapa seria impossível.

Em especial, à minha esposa Diana Milena Cortés Patiño pelo companheirismo, amor e dedicação ao longo da realização deste trabalho.

Ao meu irmão Lucas Albin Soares e amigos Fernando Genaro e Bruno Cunha, pela companhia e abrigo na minha chegada a São Paulo.

Aos amigos Saulo Velasco, Eliana Hamasaki e Viviane Verdu Rico, que me incentivaram a vir de Belém para São Paulo e, uma vez aqui, me acolheram e auxiliaram.

Aos colegas de laboratório e pós-graduação: Will Perez, Saulo Velasco, Eliana Hamasaki, Viviane Verdu Rico, Rafael Modenesi, Ariene Coelho, Heloisa Cursi, Daniela Canovas, Catalina Serrano, Adriana Saavedra, Priscila Grisante, Nicolas Rossger, Peter Endenman, Diana Cortes, Liane Dahás, Hernando Borges, Andeson Carneiro, William Patarroyo e Andrés Ballesteros.

Especialmente à Cataliana Serrano, Arturo Clavijo e Diana Cortes. Pela ajuda, aprendizado e, principalmente, pela amizade.

Ao professor Tim Shahan e demais companheiros da Utah State University: Maggy Sweeney, Andy Craig, Rusty Nall, Jay Hinnemkamp, John Friedel, Paul Cunnigham, Brady DeHart, Charles Frye e Jillian Rung, pelo aprendizado e por receberem Diana e eu tão amavelmente durante a realização do estágio de doutorado sanduíche.

Aos meus amigos e mestres Olavo de Faria Galvão, Romariz da Silva Barros e Solange Calcagno. 
Agradeço ao Professor Gerson Yukio Tomanari por me receber em seu laboratório em São Paulo e permitir a realização deste projeto de doutorado sob sua supervisão.

As professoras Miriam Garcia Mijares e Andréia Schmidt pela leitura cuidadosa e sugestões no projeto.

Finalmente, à CAPES pela bolsa de doutorado e ao Instituto Nacional de Ciência e Tecnologia sobre Comportamento Cognição e Ensino INCT-ECCE (FAPESP processo: 08/57705-8 e CNPq processo: 573972/2008-7). 


\section{RESUMO}

Soares Filho, P. S. D. (2014). Efeito de diferentes contingências de reforço no estabelecimento de discriminações condicionais e na formação de classes de estímulos equivalentes. Tese de doutorado. Universidade de São Paulo, Instituto de Psicologia, Programa de Pós-Graduação em Psicologia Experimental.

As classes de equivalência de estímulos são produto das contingências de reforço. No entanto, as pesquisas têm utilizado apenas contingências de reforço positivo e investigado, na sua maioria, como eventos relacionados a um mesmo reforçador podem passar a compor uma mesma classe. O objetivo do presente trabalho foi avaliar o efeito de diferentes contingências de reforço, positivo e negativo, no estabelecimento de discriminações condicionais na formação de classes de equivalência em humanos. Foram realizados dois experimentos. No Experimento I, 12 participantes treinaram simultaneamente 12 relações condicionais ( $\mathrm{AB}$ e $\mathrm{BC}$ ) utilizando três arranjos de contingência de reforçamento diferentes: reforçamento positivo (Ganhar/Manter), reforçamento negativo (Manter/Perder) e uma contingência mista de reforçamento negativo e positivo (Ganhar/Perder), seguidos de testes de formação de classes de equivalência. No Experimento I, os participantes expostos aos testes de equivalência acertaram todas as tentativas de teste. Estes resultados demonstram a possibilidade de formação de classes de equivalência em uma contingência de reforço negativo, porém um possível efeito de teto impede a comparação de cada contingência na formação de classes. No Experimento II, sete participantes foram expostos ao treino de 12 relações condicionais, com classes com um maior número de nódulos $(\mathrm{AB}, \mathrm{BC}$ e $\mathrm{CD})$ utilizando apenas duas contingências de reforço (Ganhar/Manter e Manter/Perder). Em ambos os experimentos, a sequência de aquisição das discriminações e o viés inicial produzido pelas contingências de reforço negativo sugerem um impacto diferencial da punição em relação ao reforçamento. Os resultados nos testes de equivalência sugerem que a formação de classes é menos provável quando utilizada uma contingência de reforço negativo em relação a de reforço positivo. Foi discutida a generalidade da formulação sobre formação de classes de equivalência, priorizando os padrões de controle de estímulos produzido pelas diferentes contingências. Ressalta-se a necessidade de maior investigação sobre quais os efeitos do uso de contingências aversivas no controle da resposta e mais especificamente no controle de estímulos.

Palavras chave: Contingências de reforço, discriminação condicional, equivalência de estímulos, humanos. 


\begin{abstract}
Soares Filho, P. S. D. (2014). Effect of different reinforcement contingencies on conditional discrimination acquisition and equivalence class formation. Tese de doutorado. Universidade de São Paulo, Instituto de Psicologia, Programa de Pós Graduação em Psicologia Experimental.
\end{abstract}

Equivalence classes are produced by reinforcement contingencies, however, research have used exclusively positive reinforcement and investigated mostly how events related to a same reinforcer may result in the formation a same class. The aim of this study was to evaluate how different reinforcement contingencies affect the acquisition of conditional discriminations and equivalence class formation in humans. Two experiments were conducted. In Experiment I, 12 participants learned 12 conditional relations (AB BC) under three different contingencies: positive reinforcement (Gain/Maintain), negative reinforcement (Maintain/Lose) and a mixed contingency (Gain/Lose). Equivalence class test were applied subsequently. In Experiment I, participants that underwent the equivalence tests performed correctly in all trials, although a roof effect might have prevented a proper comparison of the contingencies effect. In Experiment II, seven participants learned 12 conditional relations with more nodes $(\mathrm{AB}, \mathrm{BC}$ e $\mathrm{CD})$ and two reinforcement contingencies (Gain/Maintain and Maintain/Lose). In both experiments, the conditional discrimination acquisition sequence and the initial bias produced by the negative reinforcement contingency suggest a differential effect of punishment in relation to reinforcement. The equivalence test results suggest the possibility of equivalence class formation using a negative reinforcement contingency and indicate that equivalence classes are less probable using a negative reinforcement contingency than a positive reinforcement one. The generality of the equivalence class formulation was discussed emphasizing the investigation of stimuli control patterns produced by the contingencies. The lack of knowledge about stimulus control produced by aversive contingencies was highlighted.

Key-words: Reinforcement contingencies, conditional discrimination, equivalence class formation, humans. 


\section{SUMÁRIO}

\section{INTRODUÇÃO}

Operante discriminado: Discriminação simples e condicional.

Equivalência de estímulos.

Formação de classes de equivalência e a relação resposta-reforço. 12

Efeitos das contingências de reforço (positivo vs. negativo). .20

\section{EXPERIMENTO I}

Método .28

Resultados e Discussão. .36

\section{EXPERIMENTO II}

Método. .46

Resultados e Discussão. .49

\section{DISCUSSÃO GERAL}

Diferentes arranjos das contingências (reforço positivo e negativo) e o impacto diferencial.

Diferentes arranjos das contingências (reforço positivo e negativo), formação de classes de equivalência e controle de estímulos .68 
Uma resposta é considerada operante quando sua ocorrência altera a probabilidade de ocorrência de um estímulo no ambiente e em função dessa correlação (resposta-consequência) tem sua probabilidade de ocorrência alterada (e.g. Skinner, 1953), ou seja, a determinação de que uma resposta seja considerada operante depende de que manipulações da contingência de produção do evento reforçador alterem o padrão de ocorrência da resposta. Diferentes variáveis da contingência de reforço têm mostrado afetar o responder como, por exemplo, o tipo de arranjo das contingências de reforço (positivo vs. negativo). A formação de classes de equivalência é caracterizada como um fenômeno operante e, portanto, produto das contingências de reforço.

O presente trabalho é composto de quatro partes: 1) Apresentação dos conceitos básicos da área de controle de estímulos (Operante discriminado: discriminação simples e condicional); 2) Apresentação do paradigma da equivalência de estímulos (Equivalência de estímulos); 3) Revisão (empírica e conceitual) sobre como a formulação a respeito das classes de equivalência tem abordado a relação respostareforço (Formação de classes de equivalência e a relação resposta-reforço); e 4) Descrição dos efeitos das manipulações do tipo de reforço (positivo e negativo) no responder. Em seguida, são apresentados dois experimentos nos quais foram manipulados o tipo das contingências de reforço (positivo e negativo) e seus efeitos na formação de classes de equivalência.

\section{Operante discriminado: discriminações simples e condicional}

Skinner (1969) afirma que uma descrição adequada da interação dos organismos com o ambiente deve incluir pelo menos três elementos: a ocasião na qual a resposta ocorre, a resposta em si e as consequências desta resposta. Estes três elementos 
compõem o que foi denominado de tríplice contingência e definem um operante discriminado (Skinner, 1953).

De maneira geral, o estabelecimento de um operante discriminado depende de que, na presença de um estímulo $(\mathrm{S}+)$, a ocorrência da resposta tenha como consequência um estímulo reforçador e, na ausência deste estímulo, ou na presença de outro (S $\Delta$ ou S-), a mesma resposta não produza a consequência (Skinner, 1953). O procedimento que consiste em reforçar a ocorrência de uma resposta na presença de um evento $(\mathrm{S}+)$ e não na sua ausência (ou presença de outros) (S-), foi denominado de reforçamento diferencial. A área que investiga o estabelecimento de controle pelos eventos antecedentes em uma contingência é denominada controle de estímulos (Dinsmoor, 1995; Terrace, 1966).

Quando uma história de reforçamento diferencial torna uma determinada resposta mais provável na presença de um evento antecedente $(\mathrm{S}+)$, mas não de outro (S-), tem-se a discriminação simples (Terrace, 1966; Skinner, 1953). O arranjo dos eventos que controlam uma resposta também pode envolver mais elementos do que em uma discriminação simples, e a função de $\mathrm{S}+$ de um determinado estímulo pode variar em função de outros eventos do ambiente, como, por exemplo, em uma situação de discriminação condicional (Skinner, 1950).

$\mathrm{Na}$ discriminação condicional, a função de um evento antecedente (S+) de controlar a ocorrência de uma resposta depende da ocorrência correlacionada de outro evento antecedente (estímulo condicional- Sc). Assim, o mesmo evento com função de $\mathrm{S}+$ pode passar a ter função de S- a depender do estímulo condicional apresentado, e vice-versa. Portanto, diferentemente de uma discriminação simples, na qual a função de S+ de um estímulo é "invariável”, em uma discriminação condicional o responder está 
sob controle de dois ou mais estímulos (S+e Sc - Cumming, \& Berryman, 1965). Um estímulo só possui função de $\mathrm{S}+$ na presença de um outro estímulo $\mathrm{Sc}$, caso contrário, responder na presença deste estímulo não produz reforço.

Um dos procedimentos experimentais utilizado no estabelecimento de discriminações condicionais é o matching-to-sample (MTS) ou escolha de acordo com o modelo. Neste procedimento, um estímulo modelo é apresentado e, após uma resposta ao modelo (resposta de observação), são apresentados dois ou mais estímulos de comparação. A depender do estímulo apresentado como modelo, um dos estímulos de comparação terá função de S+ e o outro de S-. Este procedimento exige o uso de, pelo menos, quatro estímulos (dois modelos e dois comparações), permitindo, assim, a condicionalidade do responder às comparações.

Como produto do estabelecimento de controle de estímulos foi observado que as contingências de reforçamento e o responder em uma situação de discriminação condicional produziam não apenas um responder discriminado, mas também que os eventos envolvidos da discriminação poderiam ser substituíveis entre si. Este fenômeno foi denominado formação de classes de equivalência (Sidman \& Tailby, 1982; Sidman, 2000) e representa uma parte importante da pesquisa em controle de estímulos atualmente.

\section{Equivalência de estímulos}

Um dos principais interesses da análise do comportamento é explicar como eventos arbitrariamente relacionados se substituem na função de controlar uma resposta, mesmo quando estes eventos foram indiretamente relacionados (Deacon, 1997; Dickins \& Dickins, 2001; Sidman, 1994; Skinner, 1957). A emergência de relações arbitrárias entre estímulos não explicitamente treinadas, a partir de um treino condicional, foi 
assumida por Sidman (1994) como uma evidência de formação de classes de equivalência.

Sidman e Tailby (1982), utilizando uma analogia com o modelo matemático da teoria de conjuntos, propuseram um modelo descritivo da formação de classes de equivalência. Segundo os autores, a partir do treino de discriminações condicionais arbitrárias, a manutenção do responder quando os estímulos destas contingências são recombinados (de maneira condizente com a demonstração das propriedades de reflexividade, simetria e transitividade) permite inferir a formação de classes de equivalência entre os elementos relacionados durante o treino.

Por exemplo, após o treino das discriminações condicionais AB (relações A1B1 e A2B2) e BC (relações B1C1 e B2C2), os sujeitos são apresentados a tentativas de teste, nas quais os estímulos são recombinados. Estas recombinações podem estar de acordo com a propriedade de reflexividade, quando os estímulos são recombinados com eles mesmos (A1A1, B1B1, A2A2 etc.), de simetria, quando é invertida a ordem dos estímulos diretamente relacionados (B1A1, B2A2, C1B1 e C2B2) e de transitividade, quando são apresentados elementos que não foram diretamente relacionados mas estão relacionados a um elemento em comum (A1C1 e A2C2). Um teste capaz de combinar as propriedades de simetria e de transitividade foi denominado de teste de equivalência e apresenta elementos não relacionados diretamente, invertendo suas ordens de apresentação (C1A1 e C2A2). Nenhuma das relações condicionais apresentadas nos testes é explicitamente treinada. Deste modo, a manutenção do desempenho nestas tentativas demonstra a existência de classes de equivalência, isto é, demonstra que as relações estabelecidas entre os estímulos são relações de equivalência e que, portanto, os elementos inicialmente relacionados nas discriminações condicionais são substituíveis entre si (Sidman \& Tailby, 1982). 
A demonstração da formação de classes de equivalência em experimentos com participantes humanos tem sido realizada com relativa facilidade (e.g., Sidman \& Tailby, 1982, Sidman, Kirk, \& Willson-Morris, 1985). No entanto, sua demonstração em sujeitos não-humanos não tem sido alcançada com a mesma facilidade (e.g., Sidman et al., 1982), produzindo uma série de controvérsias a respeito da origem das classes de equivalência. Tais controvérsias produziram diferentes proposições a respeito da origem das classes de equivalência. Uma dessas posições, a proposta da teoria dos quadros relacionais (Hayes, Barnes-Holmes, \& Roche, 2001), postula a necessidade de um treino de múltiplos exemplares pela comunidade verbal e formação de quadros relacionais arbitrariamente aplicáveis. Por sua vez, a teoria de nomeação postula a necessidade de um repertório verbal mínimo de nomeação (Dugdale \& Lowe, 2000; Horne \& Lowe, 1996). Há propostas que baseiam a ocorrência do fenômeno em relações predominantemente respondentes, a exemplo das propostas feitas por Hayes (1992) e Tonneau (2001, ver revisão de Clayton \& Hayes, 1999).

Em outra direção, alguns autores têm sugerido que os resultados negativos de demonstração da formação de classes de equivalência se devem à incoerência entre as relações de controle de estímulos planejadas pelo experimentador e as que efetivamente exercem controle sobre as respostas do sujeito experimental. Desta forma, durante o treino de relações condicionais, apesar de o sujeito ter alcançado o critério de desempenho (responder consistentemente nas comparações corretas), a propriedade do estímulo que controla o responder do sujeito não foi a planejada pelo experimentador, resultando na produção de resultados negativos de formação de classes de equivalência (Dube \& McIlvane, 1996; McIlvane et al., 2000). Esta "propriedade física, relação estrutural ou propriedade de controle de um operante discriminado" (ex. o controle por 
uma parte ou posição do estímulo) foi denominada de Topografia de Controle de Estímulos (TCE, McIlvane \& Dube, 2003, p. 195).

A afirmação de que os resultados negativos com sujeitos não-humanos se devem a incoerência entre as TCEs planejadas e as efetivamente geradas ganha força com a demonstração de algumas propriedades das relações de equivalência em experimentos que utilizam sujeitos não-humanos. Estas demonstrações têm sido possíveis em vista da utilização de procedimentos mais precisos no controle das TCEs estabelecidas durante os treinos das discriminações condicionais, como, por exemplo, o controle da ordem de apresentação temporal (Frank \& Wasserman, 2005; Urcuioli, 2008), o controle do responder por rejeição (Schusterman \& Kastak, 1993) e o uso de testes com reforçamento (Schusterman \& Kastak, 1993, Velasco, Huziwara, Machado, \& Tomanari, 2010).

Formação de classes de equivalência e a relação resposta-reforço

Sidman $(1994,2000)$ afirma que a contingência de reforçamento pode produzir dois resultados: as unidades analíticas e as relações de equivalência. Em uma situação na qual uma resposta $(R)$ produz uma consequência $(S)$ e essa consequência tem função reforçadora - aumentando a frequência desta resposta (reforçamento operante) - a relação entre estes dois elementos (R-S) compreenderia uma unidade analítica de dois termos. Da mesma maneira, em uma situação de discriminação simples, a relação entre o evento antecedente, a resposta e a consequência (S-R-S), seria denominada de uma unidade analítica de três termos. Por fim, em uma situação de discriminação condicional, na qual a unidade de três termos está sob controle de um estímulo condicional (Sc - S - R - S) (Cumming \& Berryman, 1965), tem-se uma unidade de quatro termos. 
O segundo produto das contingências de reforçamento seriam as relações de equivalência, que consistiriam "dos pares ordenados de todos os elementos positivos que participam em uma contingência de reforçamento" (Sidman, 2000, p 128). Portanto, os elementos de uma contingência que estão correlacionados com o mesmo reforçador deveriam ser substituíveis entre si no controle das respostas e, atestadas as propriedades definidas pelo modelo descritivo, passariam a ser considerados uma classe de estímulos equivalentes (Sidman, 2000).

Assim, Sidman $(1994 ; 2000)$ assume a equivalência de estímulos como um processo comportamental básico e exclusivamente operante. Assim, tal qual a discriminação e a generalização, as classes de equivalência são produto direto das contingências de reforçamento.

Sidman (1994, 2000), também afirma que os eventos com função discriminativa que controlam respostas diferentes passariam a ser substituíveis entre si quando estão relacionados a um mesmo reforçador, cumprindo os critérios de uma classe de equivalência. Da mesma maneira, assim como os estímulos antecedentes, afirma que os eventos reforçadores passariam a compor as classes.

A partir destas afirmações sobre a formação de classes, os estudos se concentraram em avaliar duas características: 1) se os estímulos reforçadores utilizados no estabelecimento de uma discriminação condicional podem exercer função de modelo ou comparação da discriminação correspondente e 2) se treinos prévios com uso de reforços específicos podem fazer com que os elementos relacionados aos mesmos reforçadores sejam substituíveis entre si (Barros, Lionello-Denolf, Dube, McIlvane, 2006; Dube, McIlvane, Mackay \& Stoddard; 1987; Dube, McIlvane, Maguire, Mackay, \& Stooddard, 1989; Schenk, 1994; Dube \& McIlvane, 1995; Pelick, 2005). 
Dube et al. (1987) realizaram um conjunto de experimentos por meio do qual avaliaram se os elementos reforçadores poderiam, também, exercer função de modelo e comparação (Experimento I), se treinos posteriores permitiriam a expansão das classes já estabelecidas (Experimento II), e se a reversão dos reforçadores produziria uma reversão das classes (Experimento III). No primeiro experimento, dois adultos com atraso severo no desenvolvimento foram submetidos a treinos de MTS por identidade com os objetos (O), imagens (S) e comidas (F), e de MTS arbitrário auditivo-visual e visual-visual entre palavras faladas $(\mathrm{N})$, objetos $(\mathrm{O})$ e imagens $(\mathrm{S})$, simultaneamente. Cada conjunto de estímulos era composto por dois elementos (e.g. o conjunto O era composto por $\mathrm{O} 1$ e O2). Assim, as escolhas corretas dos estímulos N1, O1, S1 e F1 eram consequenciadas com F1, e as escolhas corretas dos eventos N2, O2, S2 e F2, com F2. Após alcançar os critérios de treino, os participantes foram submetidos a tentativas de teste de simetria e transitividade, bem como a tentativas nas quais os estímulos F1 e F2 funcionavam como modelo e como comparação. Ambos os participantes responderam corretamente nos testes de simetria e transitividade e nos testes subsequentes de inclusão dos reforçadores na classe, produzindo assim, o primeiro dado a demonstrar a inclusão dos estímulos reforçadores na classe.

No Experimento II, Dube et al. (1987) realizaram treinos de MTS de identidade com outros dois elementos (X1 e X2) utilizando o procedimento de reforçamento específico com os mesmos reforçadores do experimento anterior (F1 e F2) com a finalidade de verificar se o uso do procedimento de reforçamento específico permitiria a ampliação das classes anteriormente formadas. Foram realizadas tentativas de testes nas quais os estímulos X1 e X2 eram apresentados como modelo e comparação em tentativas nas quais os estímulos das classes anteriormente formadas (elementos $\mathrm{N}, \mathrm{O}$ e S) eram apresentados de maneira consistente com os reforçadores específicos. Os dois 
participantes responderam de acordo com a inclusão dos elementos X1 e X2, nas classes N1, O1, S1 e F1; e N2, O2, S2 e F2, respectivamente.

Em seguida, no Experimento III de Dube et al. (1987), as contingências do treino da identidade dos elementos $\mathrm{X} 1$ e X2 foram revertidas, de maneira que agora responder corretamente ao estímulo $\mathrm{X} 1$ produzia a consequência $\mathrm{F} 2$ e responder corretamente no X2 produzia F1. Este experimento teve como finalidade verificar se a reversão das contingências de reforçamento reorganizava os elementos X1 e X2 nas classes anteriores. Para tanto, após a reversão das contingências, foram realizadas tentativas de teste similares às do Experimento II. Mais uma vez, neste experimento, os resultados sugeriram que a reversão das contingências de reforçamento reorganizou os elementos em novas classes de equivalência em função do uso de reforçadores específicos. Assim, Dube et al. (1987) concluíram que, em um treino condicional utilizando consequências específicas para cada classe de estímulos, os estímulos reforçadores também passam a compor classes de equivalência.

Dube et al. (1989) realizaram um experimento similar ao experimento de Dube et al. (1987), eliminando, porém, o treino de MTS de identidade com os estímulos reforçadores e utilizando apenas os estímulos de modalidade visual. Esta manipulação foi realizada para avaliar se os resultados de inclusão dos reforçadores na classe obtidos por Dube et al. (1987) poderiam ser produto da participação prévia dos estímulos como modelo e comparações no treino de identidade. Os resultados obtidos por Dube et al. (1989) replicaram os obtidos por Dube et al. (1987) e excluíram a hipótese de que a inclusão dos estímulos reforçadores na classe tenha ocorrido em função do treino de identidade. 
Kastak, Schursterman e Kastak (2001) realizaram um conjunto de experimentos com leões marinhos cujos resultados sugerem que o uso de reforços específicos para cada classe facilitaria a formação de classes funcionais de estímulos por reversões repetidas (Experimento I). Da mesma maneira, sugerem que elementos novos, utilizados apenas em um treino de discriminação simples com os mesmos reforçadores específicos de cada classe, fazem com que eles posteriormente possam ser incluídos nas classes já existentes (Experimento III).

As conclusões obtidas por Dube et al. (1987; 1989), bem como os dados de Kastak et al.(2001) sobre a inclusão dos elementos reforçadores nas classes de equivalência, foram ampliados para crianças com desenvolvimento típico (Schenk, 1994) e crianças com autismo (Pelick, 2005). Foi verificada, também, a possibilidade de formação de classes de equivalência como produto apenas de treinos de identidade com reforçamento específico (e.g. Barros, Lionello-DeNolf, Dube, \& McIlvane, 2006; Dube \& MacIlvane, 1995; Schenk, 1994, Experimento II). Estes dados corroboram a proposição de Sidman (2000) de que os elementos correlacionados com um mesmo reforçador passariam a compor uma classe de equivalência e que, quando utilizados reforçadores específicos, os reforçadores passariam a compor as classes de equivalência.

Uma questão levantada por Sidman (2000) sobre a formação de classes de equivalência e sua relação com o reforçamento é: se os eventos relacionados a um mesmo reforçador passam a ser substituíveis entre si, compondo uma classe de equivalência, por que em diversos experimentos (e.g., Saunders, \& Spradlin, 1989; Sidman \& Tailby, 1982; Sidman, Kirk, \& Wilson-Morris, 1985), nos quais as relações condicionais são mantidas por um mesmo reforçador, os participantes demonstram a formação de mais de uma classe de estímulos equivalentes? Por que, se o estímulo reforçador é único e utilizado para todas as possíveis classes, todos os elementos 
envolvidos no treino não se fundem, passando a compor uma única classe de equivalência?

No que concerne à questão apontada no parágrafo anterior, Sidman (2000) realiza um ajuste em sua teoria e propõe que, como produtos de uma contingência de reforçamento, as unidades analíticas teriam precedência em relação à formação de classes de equivalência. Assim, quando o reforço representa um conflito - é comum a duas classes - "com a finalidade de separar a classes, o reforço não funcionaria como membro da classe. A contingência toma precedência quando o reforçamento é comum, forçando que ele saia (drop up) da classe" (Sidman, p. 132).

Minster, Jones, Elliffe, e Muthukumaraswamy (2006) avaliaram as predições teóricas de Sidman (2000) sobre a precedência das unidades analíticas. Neste experimento, participantes humanos foram submetidos ao treino conjunto de relações condicionais (A1B1, B1C1, A2B2, B2C2, A3B3, B3C3, A4B4 e B4C4) de maneira que responder corretamente produzia a apresentação de figuras (imagens de dinheiro, ingressos para concertos ou doces). Foi utilizado um procedimento de reforçamento específico, no qual responder corretamente em tentativas da Classe 1 produzia a apresentação de imagens de dinheiro e nas tentativas da Classe 2, imagens de ingressos. Tentativas das Classes 3 e 4 produziam a mesma consequência (imagens de doces). Após alcançar o critério de desempenho, os participantes eram primeiramente submetidos aos testes de classes de equivalência e, em seguida, submetidos a testes nos quais os estímulos reforçadores funcionavam como modelo e comparação para os outros estímulos do treino, avaliando a possibilidade de inclusão dos estímulos reforçadores na classe. 
Uma característica do procedimento de Minster et al. (2006) é: tendo em vista que as classes três e quatro (A3B3C3 e A4B4C4) estavam relacionadas à mesma consequência, a predição teórica realizada por Sidman (2000) exigiria que, quando este elemento fosse apresentado como modelo e como comparação, o responder não fosse consistente com a formação de classes. No entanto, os resultados mostraram que os participantes responderam consistentemente com a formação de classes nas tentativas tradicionais de teste de formação de classes de equivalência (acima de $85 \%$ de acerto) e que a maioria dos participantes (cinco de seis) demonstrou responder consistente (pelo menos $85 \%$ acertos) nas tentativas em que os reforçadores foram utilizados como estímulos.

Minster et al. (2006) afirmam que seu experimento permite algumas considerações metodológicas que levariam a uma intepretação alternativa, a exemplo da possibilidade de que um responder por rejeição tenha produzido os resultados nos testes com os reforçadores; consideram, porém, esta possibilidade pouco provável. Este experimento apresenta duas contribuições para a presente discussão. Primeiro, ressalta a necessidade de avaliação empírica de algumas das predições teóricas da formulação de Sidman (2000) ainda não avaliadas. Em segundo lugar, sugere que, a depender dos resultados empíricos, pode ser necessário alterar a organização conceitual (a maneira como se concebe) sobre a formação de classes de equivalência.

Ao levantar a produção empírica sobre a relação entre formação de classes de equivalência e as contingências de reforçamento podemos observar que: a) todos os experimentos utilizaram apenas contingências de reforço positivo e b) os experimentos concentraram-se exclusivamente em realizar variações das predições de Sidman (1994, 2000) sobre a inclusão do estímulo reforçador na classe e sobre a possibilidade de 
estabelecimento de classes a partir do treino com reforços específicos ${ }^{1}$. Desta maneira, são deixadas de lado outras variações das contingências de reforçamento, como por exemplo, o tipo de contingência (reforçamento positivo e negativo) ou manipulações das consequências, como por exemplo, o uso de diferentes probabilidades de reforçamento.

Como mencionado, Sidman (2000) afirma que as classes são compostas "dos pares ordenados de todos os elementos positivos de uma contingência de reforçamento" (p. 128). Esta afirmação descreve o que poderia acontecer em uma situação de reforçamento positivo, na qual os elementos que devem controlar a resposta estão correlacionados com a produção do reforçador e, portanto, passariam a compor a classes de equivalência. Porém, qual é a predição em uma situação de reforçamento negativo, na qual a escolha de um estímulo é mantida pela correlação do estímulo incorreto com um evento aversivo?

Adicionalmente, consideramos a afirmação de que a formação de classes de equivalência é produto de uma contingência de reforçamento, no mínimo, prematura. Isto porque não foram encontrados (pelo menos até o alcance da busca realizada pelo autor) experimentos nos quais se observassem mudanças na probabilidade de formação de classes de equivalência quando manipuladas características das contingências de reforçamento.

Tendo em vista a referida necessidade de avaliar como manipulações das contingências de reforço podem afetar a formação de classes de equivalência, este

\footnotetext{
${ }^{1}$ Adicionalmente, alguns estudos sugerem que a resposta exigida no estabelecimento dos controles de estímulos pode também compor as classe (e.g. Manabe, Kawashima \& Staddon, 1995), no entanto, o presente trabalho pretendeu focar as pesquisas sobre como os eventos ambientais (estímulos discriminativos e reforçadores) passam a substituir-se no controle da resposta.
} 
trabalho irá apresentar um conjunto de dados sobre o efeito de variações nas contingências de reforço, como, por exemplo, o uso de diferentes tipos de contingências de reforço (positivo vs. negativo) e diferentes probabilidades de reforçamento na manutenção e no estabelecimento de uma tarefa discriminada (e.g. Magoon \& Critchfield, 2008; Rasmussen \& Newland, 2008). Será assinalada, assim, a necessidade de avaliar o efeito e manipulações das contingências de reforçamento na formação de classe de estímulos equivalentes.

Efeitos de manipulações das contingências de reforço (positivo vs. negativo) na aquisição de discriminações condicionais.

A noção de que o comportamento é afetado pelas suas consequências (Lei do efeito) é intrínseca a quase todas as definições de comportamento operante (e.g. Herrnstein, 1970; Skinner, 1953), no entanto, as consequências podem afetar o comportamento de diferentes maneiras. Por exemplo, quando uma resposta tem a probabilidade de ocorrência aumentada em função de sua correlação com a produção de um evento no ambiente, este procedimento é denominado de reforçamento positivo e o evento de reforçador. Se observada uma redução na probabilidade da resposta em função da correlação com a produção de um evento ou um aumento da probabilidade de resposta correlacionada com a retirada, o procedimento é denominado, respectivamente, de punição positiva e reforçamento negativo, enquanto o evento é classificado como um evento aversivo $^{2}$ (Skinner, 1953; Catania, 1998).

\footnotetext{
${ }^{2}$ Apesar de reconhecer a dificuldade em classificar os eventos como aversivos (e.g. Michael, 1975 Hunzinker, 2011), o presente texto utilizará a nomenclatura mais comum e levará em consideração o processo de aumento ou redução na frequência da resposta em função da apresentação dos eventos (e.g. Catania, 1998).
} 
Um debate amplamente explorado na literatura analítico comportamental diz respeito à simetria da lei do efeito, o efeito diferencial de consequências positivas e aversivas no comportamento (Crichfield \& Magoon, 2001;Farley \& Fantino, 1978; Magoon \& Crichfield, 2003, 2008; Rasmussen \& Newland, 2008). Magoon e Critchfield (2008) sugerem que o debate entre o efeito do uso de consequências positivas e aversivas pode ser elaborado em dois níveis de discussão.

No primeiro nível, são considerados os mecanismos que podem estar envolvidos no controle do comportamento produzido a partir do uso de eventos positivos/apetitivos ou aversivos. Neste nível são postuladas duas hipóteses: 1) a hipótese dos mecanismosdiferenciais (differential-mechanism hypothesis), na qual as diferenças observadas seriam explicadas a partir de diferentes mecanismos de ação em cada tipo de evento, como por exemplo, que o reforçamento positivo se daria em função das contingências operantes de fortalecimento da resposta e que a punição ou reforçamento negativo ocorreriam em função de comportamentos eliciados pelos eventos aversivos (e.g. Dinsmoor, 1954; Skinner, 1953); 2) a hipótese dos mecanismos-comuns (commonmechanism hypothesis), segundo a qual reforço positivo e punição/reforçamento negativo constituiriam manifestações opostas de um mesmo mecanismo comportamental (e.g. Herrnstein \& Hineline, 1966; Schuster \& Rachlin, 1968). Apesar da produção a respeito dos mecanismos envolvidos no reforçamento e na punição, este debate parece não haver sido resolvido (e.g., Critchfield, Paletz, MacAleese, \& Newland, 2003; Dinsmoor, 2001; Hineline, 1984). Adicionalmente, a discussão dos mecanismos envolvidos no reforço e na punição não é alvo do presente trabalho.

No segundo nível de discussão são considerados os impactos na alocação do comportamento (escolha) em função do uso de reforço ou punição. Neste contexto, são levantadas duas hipóteses: 1) a hipótese do impacto-comum (common-impact 
hypothesis), a qual sugere que a punição e o reforçamento têm um efeito simétrico e exercem o mesmo grau de controle no comportamento (e.g. Farley \& Fantino, 1978); 2) a hipótese do impacto-diferencial (differential-impact hypothesis), a qual sugere que reforçamento positivo e punição têm um impacto assimétrico e exercem diferentes graus de controle na escolha (e.g. Baumeister, Bratslavsky, Finkenauer, \& Vohs, 2001; Kahneman \& Tversky, 1979; Magoon \& Crichfield, 2001; Rasmussen \& Newland, 2008).

Uma característica desta área é que boa parte dos estudos têm sido realizados com participantes humanos e utilizado procedimentos de tomada de decisão, em que os participantes escolhem entre duas situações hipotéticas que postulam diferentes probabilidades de ganhos ou perdas, usualmente de dinheiro/investimentos (e.g. Kahneman \& Tversky, 1979, ver revisão de Baumeister, et al., 2001). Poucos estudos, provenientes da análise do comportamento, foram realizados avaliando os diferentes impactos do reforçamento e punição no controle do comportamento em situações de escolha (e.g. Magoon \& Critchfield, 2008; Rasmussen \& Newland, 2008).

Em sua maioria as pesquisas com não-humanos têm avaliado especificamente qual modelo descreve melhor o efeito da punição na alocação do comportamento, se a punição diminui a probabilidade de ocorrência da resposta punida (modelo subtrativo) ou se ele aumenta a probabilidade de ocorrência da resposta não punida (modelo aditivo). De maneira geral, os dados tem corroborado um modelo subtrativo para punição em uma situação de escolha (e.g. de Villiers, 1980). No entanto, devido ao uso de eventos aversivos e reforçadores qualitativamente diferentes (e.g. choque vs. comida) pesquisas com não-humanos têm dificuldades metodológicas em comparar diretamente os impactos da punição e do reforço (Critchfield, et al., 2003; Hamasaki \& Tomanari, 2009; ver revisão de Lie \& Alsop, 2007). 
Como uma alternativa à impossibilidade de comparação entre os efeitos de eventos qualitativamente diferentes, recentemente, alguns autores propuseram a realização de pesquisas com humanos em situação de escolha, utilizando o ganho e perda de dinheiro/pontos como eventos reforçadores e aversivos, possibilitando uma comparação direta dos impactos do reforço e da punição (Critchfield \& Magoon, 2001; Rasmussen \& Newland, 2008) $)^{3}$.

Com o objetivo de comparar o impacto do reforço e da punição, Rasmussen e Newland (2008) realizaram um experimento em que humanos foram submetidos a uma situação de escolha concorrente, na qual cada escolha ou estímulo era correlacionado a diferentes probabilidades de reforço e punição (ganhos e perdas de dinheiro). No experimento, uma tela de computador era dividida verticalmente em duas partes (direita e esquerda) e no meio de cada metade aparecia um pequeno quadrado colorido (vermelho ou verde). Em uma primeira fase, clicar com o mouse em cada um dos quadrados produzia, em um esquema de intervalo variável (VI), o aparecimento de uma figura no centro da tela indicando o ganho de 4 centavos de dólar $(+4 \mathrm{c})$. Nesta fase, foram utilizados os esquemas concorrentes VI 12s -VI 60s, VI 20s - VI 20s e VI 60s VI 12s (razão de reforço de 1:5, 1:1 e 5:1, respectivamente).

Na segunda fase, foram utilizados os mesmos esquemas de reforçamento, porém para um dos componentes era sobreposto a apresentação de uma figura, indicando a perda de 4 centavos de dólar (-4c) em um esquema de VI 1.25 vezes o esquemas no qual a punição estava sendo sobreposta. Por exemplo, quando utilizado um esquema de

\footnotetext{
${ }^{3}$ Diversos experimentos têm sido realizados com participante humanos, utilizando ganho e perda de pontos como consequência, a fim de comparar qual modelo descreve mais adequadamente o efeito da punição. Os experimentos, assim como os experimentos com não-humanos, corroboram o modelo subtrativo de punição (Critchfield, et al., 2003; Lie \& Alsop, 2009; Magoon \& Critchfield, 2008).
} 
concorrente VI 12s - VI 60 para ganhos, o esquema de VI 12s poderia funcionar de maneira simultânea a um VI 15s para perda (esquema 1.25 vezes o esquema de reforço sobreposto). Em ambas as fases, cada esquema esteve em vigor até os participantes alcançarem o critério de estabilidade. A sequência dos esquemas e a sobreposição foram balanceadas para evitar efeito de ordem.

$\mathrm{Na}$ primeira fase, os resultados mostraram que os ganhos funcionaram como reforçadores: os participantes distribuíram o responder proporcionalmente à probabilidade de ganhos. Na segunda fase, foi mostrado que as perdas funcionaram como punidores, afastando o responder da escolha correlacionada com a punição. Quando analisada a distribuição das resposta em relação à distribuição total das consequências (proporção de reforços menos a proporção de punidores) foi observado um viés, na direção oposta à escolha que produzia perdas, três vezes maior do que na situação em que não eram produzidas perdas, indicando assim, um efeito assimétrico entre reforço e punição.

Isto significa que, apesar da existência de certa controvérsia e de um número pequeno de experimentos, os estudos que avaliaram o impacto diferencial exercido pelo reforço positivo e a punição, utilizando tarefas de escolha, têm corroborado a hipótese do impacto-diferencial, sugerindo que as contingências aversivas controlam o comportamento mais "fortemente" que as contingência positivas (Critchfield \& Magoon, 2001; Hamasaki \& Tomanari, 2009; Kahneman \& Tversky, 1979; Lie \& Alsop, 2009; Rasmussen \& Newland, 2008; Taylor, 1991).

As pesquisas que suportam a hipótese do impacto diferencial, apontadas até o presente momento, utilizam geralmente uma situação de escolha concorrente, na qual dois estímulos são apresentados simultaneamente e responder a cada um deles está 
correlacionado com um esquema ou proporção de reforço. Este arranjo se assemelha a uma situação de discriminação simples simultânea, na qual o controle do responder na presença de um evento antecedente, em função da contingência de reforçamento, é "invariante" (como mencionado anteriormente).

Lie e Alsop (2009; Experimento 1), com o objetivo de avaliar o uso de ganho e perda de pontos como reforçadores e punidores ${ }^{4}$, utilizaram um procedimento de "detecção de sinais" com humanos (também considerado um tipo de discriminação condicional), em que uma tela de computador com um quadrado central composto por bonecos de duas cores (azul e amarelo) era apresentada aos participantes. Logo abaixo do quadrado central com os bonecos havia dois botões, em um escrito "azul" e no outro escrito "amarelo". A cada tentativa, o número de bonecos azuis e amarelos no quadro central era alterado e o participante era instruído a responder no botão que correspondia à cor com maior número de bonecos.

Para um grupo de participantes (grupo A), responder corretamente produzia o aparecimento de uma frase indicando o ganho de pontos. Neste grupo, todos os participantes foram submetidos a quatro condições em que eram variadas as probabilidades de reforço relativas entre as opções (correta vs. errada). As distribuições utilizadas foram de 5:1, 2:1, 1:2 e 1:5. Para um segundo grupo (grupo B), a proporção de reforços entre as opções foi mantida (1:1) e sobreposto ao esquema de reforçamento um esquema em que respostas incorretas produziam o aparecimento de uma frase indicando a perda de pontos (reforçamento negativo). De maneira semelhante à condição do grupo A, para este grupo a probabilidade relativa de perda de pontos por

\footnotetext{
${ }^{4}$ Este era o objetivo especifico do Experimento 1 de Lie e Alsop (2009). Conforme mencionado previamente, os demais experimentos ( 2 e 3 ) tiveram como objetivo comparar as duas hipótese da punição (subtrativa e aditiva).
} 
escolher o incorreto nas condições foi de 5:1, 2:1, 1:2 e 1:5. Os participantes de ambos os grupos passaram por uma condição de cada vez, até alcançarem estabilidade no desempenho. Ademais, a sequência de apresentação das condições foi balanceada entre os participantes de cada grupo.

Os resultados do Experimento 1 de Lie e Alsop (2009) demostraram que os pontos funcionaram como reforçadores para os participantes do grupo A, produzindo um padrão de respostas corretas diretamente proporcional à distribuição de reforços, e que a perda de pontos funcionou como evento aversivo para os participantes do grupo $\mathrm{B}$, produzindo um responder na opção correta inversamente proporcional à distribuição dos eventos aversivos.

O experimento de Lie e Alsop (2009) é relevante para a presente trabalho por uma série de razões. Primeiramente, demonstra que ganho e perda de pontos podem ser utilizados como eventos reforçadores e aversivos da mesma maneira que o ganho e a perda de dinheiro. Em segundo lugar, apresenta os eventos aversivos pela escolha das comparações incorretas, configurando uma contingência de reforçamento negativo, ao invés de utilizar os eventos aversivos sobrepostos ao reforçamento na escolha da comparação correta, como utilizado por Rasmussen e Newland (2008). Por último, diferentemente dos outros procedimentos que avaliam o efeito da punição, este experimento utiliza um procedimento de discriminação condicional, estendendo a possibilidade de investigação dos efeitos do uso de reforçadores e aversivos para fenômenos mais tipicamente investigados com este procedimento, a exemplo da equivalência de estímulos.

O conjunto de dados apresentado sugere que o estabelecimento de uma resposta operante é diferencialmente afetado pelo tipo de arranjo de reforçamento. As pesquisas 
na área de equivalência de estímulos se concentram na avaliação da formação (ou ampliação) de classes por elementos que estiveram relacionados apenas com o mesmo reforçador (e.g., Dube et al., 1987, 1989). Tendo em vista que a formação de classes de equivalência, assim como a resposta operante, é considerada produto direto das contingências de reforçamento (Sidman, 2000), seria a formação de classes de equivalência afetada diferencialmente a depender do arranjo das contingências, como, por exemplo, por meio do uso de reforçamento positivo e negativo?

Uma demonstração de que as classes de equivalência são afetadas diferencialmente pelas contingências de reforçamento, tal qual a distribuição da resposta operante, daria suporte à formulação apresentada por Sidman $(1994,2000)$ de que o reforço constitui uma variável relevante para a formação das classes. Na mesma direção, uma demonstração de que a formação de classes é possível, a partir de uma contingência de reforçamento negativo, sugeriria a necessidade de ampliar as afirmações sobre as origens das classes de equivalência para quando utilizada uma contingência que envolva a produção de eventos aversivo, como, por exemplo, a de reforço negativo e até mesmo de punição.

Assim, os dois experimentos seguintes tiveram como objetivo avaliar o efeito de diferentes contingências de reforçamento - reforço positivo e negativo (ganho e perda de pontos)- no estabelecimento de discriminações condicionais e na formação de classes de equivalência.

Nestes experimentos, foi utilizada uma contingência de reforço negativo, na qual os participantes perdem pontos ao escolher o estímulo incorreto e mantêm os pontos por escolher o correto. Neste sentido, responder no correto evita a perda de pontos, versus uma contingência de reforçamento positivo, na qual os participantes ganham pontos por 
responder no estímulo correto e mantêm os pontos por escolher o estímulo incorreto. Foi utilizado um delineamento de sujeito único em que cada participante foi submetido simultaneamente ao treino de diferentes relações condicionais a partir de contingências de reforçamento diferentes. Após o estabelecimento das discriminações condicionais, cada participante foi exposto a testes de formação de classes de equivalência.

\section{EXPERIMENTO I}

\section{MÉTODO}

\section{Participantes}

Participaram do experimento 12 adultos com desenvolvimento típico, estudantes universitários, recrutados na Universidade de São Paulo, por meio de cartazes e contatos pessoais. A participação no experimento foi voluntária e ocorreu mediante a assinatura de um termo de consentimento de participação livre e esclarecido [ver Anexo 1]. Era fornecido aos participantes ressarcimento referente a gastos, como deslocamento ou alimentação. O presente experimento possui aprovação do comitê de ética do Instituto de Psicologia da Universidade de São Paulo (No 14026913.2.0000.5561).

\section{Equipamentos e materiais}

A coleta de dados foi realizada individualmente em uma sala do laboratório Fred S. Keller do Instituto de Psicologia da Universidade de São Paulo. Foi utilizado um computador com um monitor, mouse e auto falantes. Um software desenvolvido em Visual Basic (VB 2010) apresentava os estímulos no monitor do computador, registrava as respostas de escolha (realizadas utilizando o botão esquerdo do mouse) e apresentava as consequências de acordo com a tarefa programada pelo experimentador.

\section{Estímulos}


Foram utilizados 18 estímulos bidimensionais (caracteres kanji, árabes e japoneses) denominados alfanumericamente de acordo com a Tabela 1. Como estímulos consequentes ao responder foram utilizadas três pontuações apresentadas no monitor $(+10,-10$ e 0$)$.

Tabela 1. Estímulos utilizados durante os procedimentos experimentais

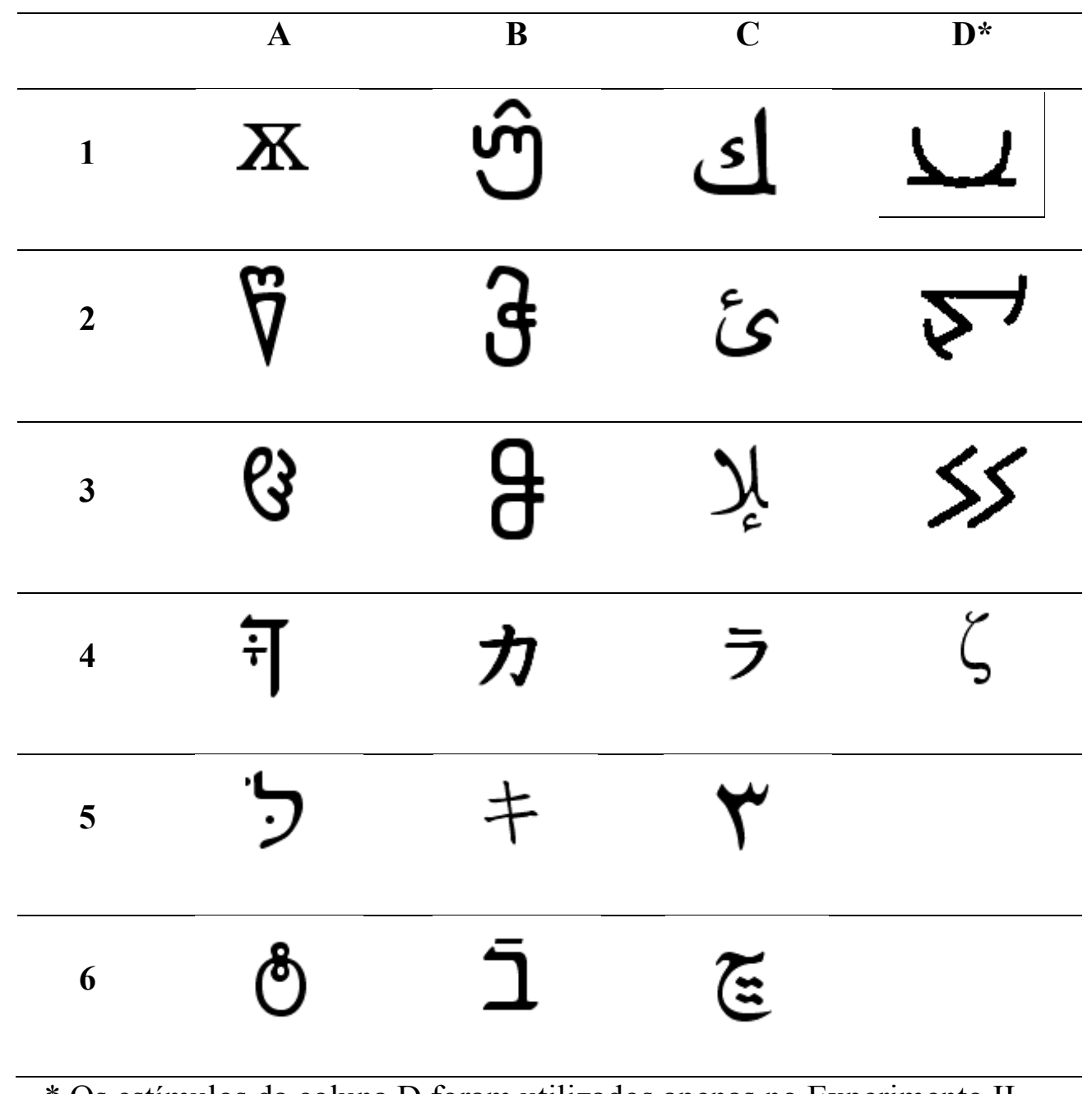

* Os estímulos da coluna D foram utilizados apenas no Experimento II.

Procedimento

Após a assinatura do termo de consentimento livre e esclarecido, o participante era encaminhado e acomodado na sala de coleta experimental. Ao participante eram apresentadas as seguintes instruções: 
"Inicialmente, aparecerá uma figura no centro da tela. Após observá-la, clique sobre a mesma. A figura desaparecerá e aparecerão outras duas figuras na parte inferior da tela, você deverá escolher e clicar sobre uma delas. Algumas escolhas produzirão ganhos, outras perdas e outras a manutenção de pontos. Sua tarefa é obter o máximo de pontos possíveis. Nas fases finais, os pontos não aparecerão, mas você deverá continuar respondendo de acordo com as combinações que aprendeu, pois o computador continuará registrando os acertos. Você deverá me avisar quando aparecer uma mensagem na tela do computador indicando a conclusão de cada uma das fases. Alguma dúvida? Podemos começar?"

Após a leitura das instruções pelo participante e o esclarecimento de possíveis dúvidas pelo experimentador, era iniciada a tarefa experimental.

\section{Tarefa experimental}

Os participantes foram submetidos ao treino de 12 relações condicionais [(A1B1, A2B2); (B1C1, B2C2); (A3B3, A4B4); (B3C3, B4C4); (A5B5, A6B6); (B5C5, B6C6)] utilizando blocos de tentativas de MTS arbitrário com atraso $0 \mathrm{~s}$ e duas escolhas. A tarefa consistiu da apresentação de blocos compostos por quatro tentativas de MTS de cada relação condicional treinada (inicialmente 48 tentativas), apresentadas em sequências randômicas. Após a aquisição de todas as relações condicionais, os participantes foram submetidos a um bloco com tentativas de teste de formação de classes de equivalência (simetria, transitividade e simetria da transitividade de todas as relações treinadas).

Uma tentativa de MTS iniciava com a apresentação de um estímulo modelo (e.g., A1) na parte superior central da tela. Após a resposta de clicar uma vez com o mouse sobre o modelo, o estímulo desaparecia imediatamente e em seguida (atraso 0), 
na parte inferior da tela, apareciam dois estímulos de comparação (e.g., B1 e B2), um à esquerda e o outro à direita. A posição dos estímulos era balanceada, de forma que todos os estímulos apareciam o mesmo número de vezes em cada posição e que um mesmo comparação não aparecia mais de duas vezes consecutivas na mesma posição.

\section{Procedimento especifico}

Responder ao estímulo programado como correto $(\mathrm{S}+)$ produzia a apresentação da consequência correta correspondente, a depender da relação treinada (e.g., responder no estímulo B1, quando A1 era apresentado como modelo, produzia a apresentação da pontuação “+10” na parte central do computador. Clicar sobre a pontuação apresentada na tela (resposta de consumação, garantindo o contato com o evento reforçador), iniciava um intervalo entre tentativas (ITI) de 1,5 segundos, durante o qual a tela permanecia sem nenhum estímulo. Após a passagem do ITI era iniciada outra tentativa. Responder ao estímulo determinado como incorreto (S-) produzia a consequência correspondente, a depender da relação treinada (e.g., responder no B2, produzia a pontuação "0") e assim como para a resposta correta, clicar sobre a consequência era seguido por um ITI de 1,5 segundos e pelo início de uma nova tentativa.

Todas as relações foram treinadas simultaneamente, porém, em cada tentativa foram treinados pares fixos de relações (e.g., sempre que o estímulo A1 ou A2 funcionava como modelo, eram apresentados como comparações os estímulos B1 e B2).

Foram utilizados três arranjos das contingências de reforçamento: 1) Arranjo de reforçamento positivo, no qual a resposta de clicar uma vez (CRF) no estímulo correto produzia no monitor “+10”, ganho de pontos (ganhar) e clicar (CRF) no estímulo incorreto produzia " 0 " (manter), ou seja, manutenção dos pontos (arranjo Ganhar/Manter); 2) Arranjo de reforçamento negativo, no qual clicar (CRF) no estímulo 
correto produzia “0” (manter) e clicar no estímulo incorreto produzia “-10" (perder), isto é, perda de pontos (arranjo Manter/Perder); 3) Arranjo combinado de reforçamento positivo e negativo, no qual clicar (CRF) no estímulo correto produzia "+10" e clicar (CRF) no incorreto "-10" (arranjo Ganhar/Perder). Em nenhum momento era apresentado um registro cumulativo dos pontos obtidos ao longo do experimento.

As relações condicionais $\mathrm{A} 1 \mathrm{~B} 1, \mathrm{~B} 1 \mathrm{C} 1, \mathrm{~A} 2 \mathrm{~B} 2$ e B2C2, foram treinadas utilizando o arranjo Ganhar/Manter, as relações A3B3, B3C3, A4B4 e B4C4 o arranjo Manter/Perder e ar relações A5B5, B5C5 e A6B6, B6C6 o arranjo Ganhar/Perder (Ver Tabela 2).

Tabela 2. Arranjo das consequências por relação condicional treinada.

\begin{tabular}{|c|c|c|c|}
\hline \multirow{2}{*}{ Arranjo } & \multirow{2}{*}{$\begin{array}{l}\text { Relações } \\
\text { treinadas }\end{array}$} & \multicolumn{2}{|c|}{ Consequências programadas } \\
\hline & & $\mathrm{S}+$ & S- \\
\hline \multirow{3}{*}{ Ganhar/Manter } & $\mathrm{A} 1 \mathrm{~B} 1, \mathrm{~B} 1 \mathrm{C} 1$ & \multirow{3}{*}{+10} & \multirow{3}{*}{0} \\
\hline & & & \\
\hline & $\mathrm{A} 2 \mathrm{~B} 2, \mathrm{~B} 2 \mathrm{C} 2$ & & \\
\hline \multirow{3}{*}{ Manter/Perder } & $\mathrm{A} 3 \mathrm{~B} 3, \mathrm{~B} 3 \mathrm{C} 3$ & \multirow{3}{*}{0} & \multirow{3}{*}{-10} \\
\hline & & & \\
\hline & $\mathrm{A} 4 \mathrm{~B} 4, \mathrm{~B} 4 \mathrm{C} 4$ & & \\
\hline \multirow{3}{*}{ Ganhar/Perder } & $\mathrm{A} 5 \mathrm{~B} 5, \mathrm{~B} 5 \mathrm{C} 5$ & \multirow{3}{*}{+10} & \multirow{3}{*}{-10} \\
\hline & & & \\
\hline & $\mathrm{A} 6 \mathrm{~B} 6, \mathrm{~B} 6 \mathrm{C} 6$ & & \\
\hline
\end{tabular}

O critério de desempenho para cada participante era de $100 \%$ de acertos para cada relação (oito tentativas) em um bloco. Assim, ao final de um bloco era contabilizada a porcentagem de acertos por relação treinada e, alcançado o critério de desempenho, esta relação era removida do bloco e o bloco seguinte apresentava apenas as outras relações, até o participante atingir o critério de desempenho com todas as relações treinadas. Esta 
manipulação teve como objetivo evitar a possibilidade de supertreino (over training) de alguma das relações, caso os diferentes arranjos de contingência produzissem uma aquisição mais rápida.

Alcançado o critério com todas as relações condicionais, era apresentado um bloco de 72 tentativas (seis de cada relação). Quando demonstrado o critério de $100 \%$ de acertos neste bloco, era iniciado o teste de formação de classes de equivalência. Caso o desempenho não tivesse sido mantido neste bloco o treino era reiniciado.

O teste de formação de classes de equivalência consistiu de um bloco com 144 tentativas, nas quais as consequências não eram apresentadas (seis de cada tipo de teste - Simetria: B1A1, B2A2, C1B1, C2B2, B3A3, B4A4, C3B3, C4B4, B5A5, B6A6, C5B5 e C6B6 Transitividade: A1C1, A2C2, A3C3, A4C4, A5C5 e A6C6 e Simetria da Transitividade: C1A1, C2A2, C3A3, C4A4, C5A5 e C6A6).

\section{Medidas}

Foram utilizadas como medidas o número total e médio de tentativas para alcançar o critério durante o treino de linha de base, o desempenho $(\log d)$ e o viés $(\log$ b) durante a tarefa de MTS, para cada tipo de contingência de reforçamento separadamente (Ganhar/Manter, Manter/Perder, Ganhar/Perder).

O desempenho durante a tarefa de MTS foi expressa utilizando o $\log d$, medida calculada para cada discriminação condicional (e.g. treino A1B1 e A2B2) por:

$$
\log d=0.5 \log \left(\frac{B_{11} B_{22}}{B_{12} B_{21}}\right)
$$

$B_{11}$ corresponde ao número de respostas no comparação correto na presença do primeiro modelo (e.g. respostas em B1 quando A1 era modelo); $B_{22}$ corresponde a 
respostas no comparação correto na presença do segundo modelo (e.g. respostas em B2 quando A2 era modelo); $B_{12}$ corresponde a respostas no comparação incorreto na presença do primeiro modelo (e.g. respostas em B2 quando A1 era modelo); e $B_{21}$ corresponde a respostas no comparação incorreto na presença do segundo modelo (e.g. repostas em B1 quando A2 era modelo).

Log d é a conversão logarítmica da média geométrica entre a razão de respostas corretas pelas incorretas. Esta medida tem sido consistentemente utilizada como uma medida de desempenho em tarefas de discriminação condicional (e.g. Lie \& Alsop, 2009; 2010; Nevin, Ward, Jimenez-Gomez, Odum \& Shahan, 2009), pois não apresenta o problema do efeito de teto, como as medidas de porcentagem de acerto, e teoricamente corresponde a uma medida independente da medida de viés (ver Davison \& Nevin, 1999; Davison \& Tustin, 1978).

Assim, quanto maior o valor de $\log d$, melhor é o desempenho dos participantes durante as discriminações condicionais; $\log d=0$ indica que o participante respondeu igualmente aos comparações corretos e incorretos (ao acaso) durante o bloco de tentativas; $\log d<0$ indica que o participante está escolhendo sistematicamente o comparação incorreto em detrimento do correto. Tendo em vista o número de tentativas por bloco, $\log d$ pode assumir valores entre 1.397 e -1.397 .

A medida de viés foi expressada pelo $\log b$ e, assim como o $\log d$, foi calculado por:

$$
\log b=0.5 \log \left(\frac{B_{11} B_{21}}{B_{12} B_{22}}\right)
$$

Os termos correspondem aos termos descritos anteriormente. Log b é a conversão logarítmica da média geométrica entre a razão de respostas a um dos 
comparações em relação ao outro. Esta medida funciona como uma medida de preferência por um estímulo em relação ao outro, ou seja, $\log b=0$ significa que não há nenhuma preferência e valores acima ou abaixo de zero indicam a preferência em direção a algum dos estímulos. Tal qual o $\log d$, o $\log b$ pode assumir valores entre 1.397 e -1.397 .

Considerando-se a necessidade de comparar as diferentes condições de treino, e, portanto, de agrupar diferentes discriminações condicionais, foi utilizado o valor absoluto da medida de preferência $(\log$ b) para permitir a realização de determinadas operações como, por exemplo, o cálculo da média de viés nos três primeiros blocos por tipo de contingência utilizada. $\mathrm{O}$ cálculo de $\log \mathrm{d}$ e $\log \mathrm{b}$ não é possível quando qualquer dos valores dos termo é igual a zero. Desta forma, foram adicionadas 0.25 a todas a células, como sugerido por Brow e White (2005).

Os valores de $\log d$ e Log b foram obtidos para cada discriminação condicional por bloco de tentativas e agrupados por tipo de contingência (Ganhar/Manter, Manter/Perder, Ganhar/Perder).

Parte da análise de dados foi realizada utilizando-se apenas os resultados dos três primeiros blocos de tentativas para cada arranjo das contingências. Esta decisão foi tomada pois: a) fornecia uma medida da etapa de aquisição das discriminações (fase inicial de treino) de maneira condizente com os objetivos aqui propostos e; b) dado que todos os participantes foram submetidos pelo menos aos três blocos iniciais (mesmo número de medições), permitia a comparação das condições fazendo uso de uma análise inferencial. 


\section{RESULTADOS E DISCUSSÃO}

Os participantes realizaram em média 1057 tentativas para completar o experimento $(S E M=102.2)$ e $792.9(S E M=112.9)$ para alcançar o critério durante o estabelecimento da linha de base.

No gráfico superior da Figura 1, à esquerda é apresentado o total de tentativas médio para alcançar o critério de linha de base em cada tipo de contingência e à direita verifica-se o dado médio para cada participante. Podemos observar que a média do número de tentativas para alcançar o critério foi maior nas discriminações treinadas utilizando a contingência Ganhar/Manter $(M=399,16 ; S E M=58,77)$ em relação às treinadas utilizando Manter/Perder $(M=230,16 ; S E M=35,37)$ e Ganhar/Perder $(M=$ 163,58; $S E M=36,09)$. Esta diferença foi considerada significativa por um teste de Friedman $\left(\chi_{(2)}^{2}=15,116, p<0,001\right)$. Adicionalmente, foram realizadas comparações dois a dois entre as condições utilizando o teste de Wilcoxon. Os testes mostraram que a condição Ganhar/Perder é significativamente diferente das condições Ganhar/Manter e Manter/Perder $(Z=-2,847$ e $-2,943$ e $p=0,002$ e 0,001 respectivamente) e marginalmente diferente ao comparar as condições Ganhar/Manter e Manter/Perder ( $Z=-2,293$ e $\mathrm{p}=0,020)$.

Nos dados individuais (gráfico superior direito, Figura 1), observa-se que 10 de 12 participantes (P2, P3, P5, P7, P8, P9, P10, P11, P12, P13) precisaram de um menor número de tentativas para alcançar o critério nas discriminações condicionais treinadas com as contingências de Ganhar/Perder, em relação às outras duas contingências utilizadas. Além disso, oito de 12 participantes (P2, P3, P8, P9, P10, P11, P12, P13) precisaram de um número maior de tentativas para alcançar o critério nas discriminações treinadas com as contingências Ganhar/ Manter em relação às demais. 
Como exceção aos padrões descritos anteriormente, o participante P4 precisou do mesmo número de tentativas para alcançar o critério em todas as discriminações condicionais, o participante P5 precisou de um maior número de tentativas na condição Manter/Perder, seguido da condição Ganhar/Manter e Ganhar/Perder, respectivamente; e o participante P6 precisou de um número maior de tentativas na condição Manter/Perder, seguido pela condição Ganhar/Perder e Ganhar/Manter, respectivamente.

O gráfico central da Figura 1 mostra, à esquerda, o $\log d$ médio nos três primeiros blocos de tentativas para cada tipo de contingência agrupando os dados de todos os participantes e à direita mostra os dados individuais. De maneira geral, podemos observar que o desempenho médio foi superior para a contingência Ganhar/Perder $(M=$ $0,54 ; S E M=0,09)$ em relação às contingências Ganhar/Manter e Manter/Perder $(M=$ 0,30; $S E M=0,09$ e $M=0.29 ; S E M=0,077$, respectivamente). A análise de variância (ANOVA) de medidas repetidas sugere uma diferença marginal entre as três condições de treino $\left(\mathrm{F}_{(2,22)}=3.389, \mathrm{p}=.052\right)$. Uma comparação dois a dois entre as condições sugere uma diferença significativa apenas entre as condições Ganhar/Perder e Manter/Perder $(\mathrm{p}=.007)$.

Nos dados individuais (gráfico central à direita, Figura 1), podemos observar que sete dos 12 participantes (P2, P5, P7, P8, P9, P10 e P12) apresentaram um desempenho $(\log d)$ médio maior, durante os três primeiros blocos de tentativas, nas discriminações condicionais treinadas com a condição Ganhar/Perder em relação às demais condições. Podemos observar, também, que sete de 12 participantes (P3, P5, P6, P8, P9, P10, P13) apresentaram um desempenho médio maior durante as discriminações condicionais da condição Ganhar/Manter em relação às discriminações da condição Manter/Perder. Apenas dois participantes (P4 e P11) apresentaram um desempenho médio maior 
durante as tentativas da condição Manter/Perder em relação às demais condições de treino.

O gráfico inferior da Figura 1 mostra, à esquerda, a média do valor absoluto de $\log b$ nos três primeiros blocos de tentativas para cada tipo de contingência e à direita são apresentados os dados individuais. De maneira geral, neste gráfico é possível observar que as discriminações treinadas utilizando a contingência Ganhar/Manter apresentavam um viés maior $(M=0,44 ; S E M=0,085)$ que pelas contingências de Manter/Perder $(M=0,28 ; S E M=0,029)$ e Ganhar/Perder $(M=0,25 ; S E M=0,035)$, respectivamente. Uma análise de variância (ANOVA) de medidas repetidas sugere uma diferença moderada entre as condições $\left(\mathrm{F}_{(2,22)}=3.266\right.$ e $\left.\mathrm{p}=.057\right)$.

Ao analisar os dados individuais (gráfico inferior à direita, Figura 1), podemos observar que seis de 12 participantes (P4, P9, P10, P11, P12 e P13) apresentaram uma média de viés maior, durante os três primeiros blocos de tentativas, para as tentativas da condição de treino Ganhar/Manter em relação às demais condições; oito de 12 participantes (P4, P5, P8, P9, P10, P11, P12, P13) apresentaram um maior viés durante as tentativas da condição Ganhar/Manter em relação às tentativas da condição Manter/Perder; e quatro de 12 (P2, P3, P6 e P7) apresentaram um maior viés médio nas discriminações da condição Manter/Perder em relação às da condição Ganhar/Manter. 

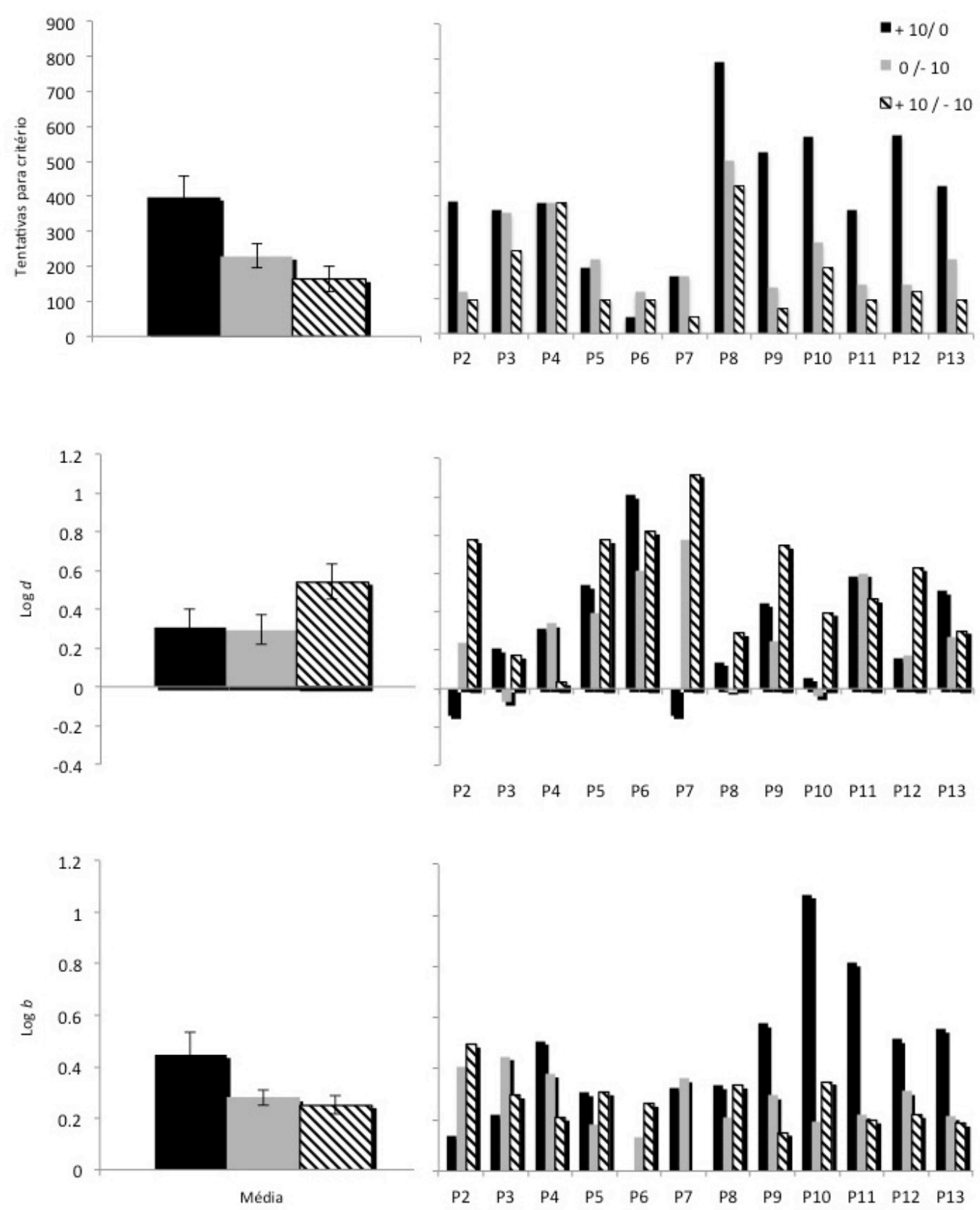

Figura 1. Gráfico superior: Média de tentativas para alcançar o critério de linha de base por tipo de contingência utilizada no treino e por participante; Gráfico central: Média de $\log d$ nos três primeiros blocos por tipo de contingência utilizada no treino; Gráfico inferior: Média do valor absoluto de $\log b$ nos três primeiros blocos por tipo de contingência utilizada no treino. Em todos os gráficos à esquerda, são apresentados os dados agrupados para todos os participantes por condição e, à direita, os dados individuais.

A Figura 2 apresenta individualmente o desempenho (log d) por bloco para cada tipo de contingência durante a fase de aquisição da linha de base (LB). Dez dos doze 
participantes (P5, P2, P6, P10, P3, P7, P11, P8, P12 e P13) alcançaram o critério de $100 \%$ de acerto das tentativas de um mesmo tipo de contingência em um bloco, primeiramente para as discriminações condicionais treinadas com a contingência Ganhar/ Perder (+10/-10), e em seguida para as discriminações treinadas com as contingências Manter/Perder (0/-10) e Ganhar/Manter (+10/0), respectivamente.

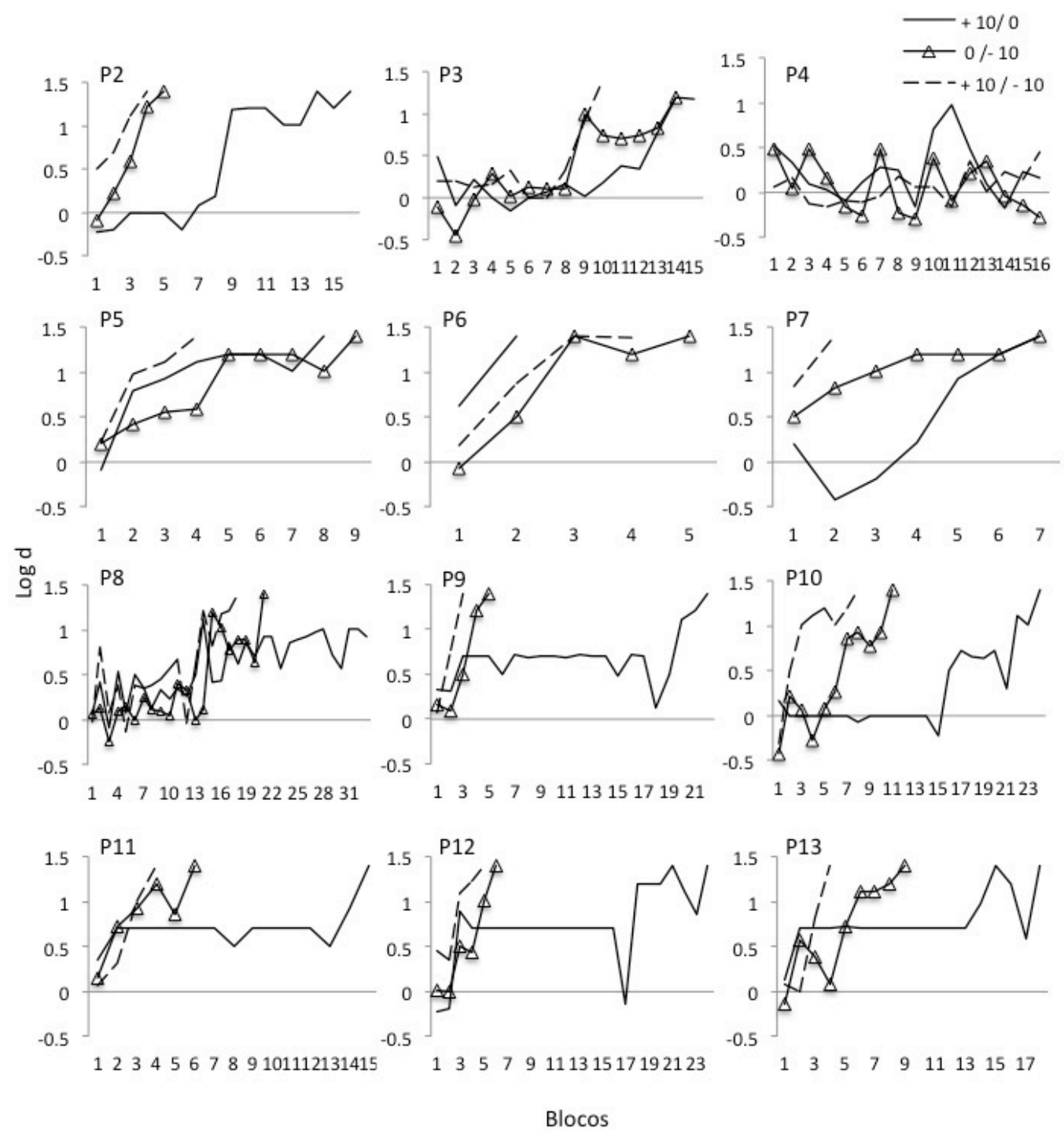

Figura 2. Log d por tipo de contingência utilizada por bloco de tentativas no treino das discriminações condicionais para cada participante.

A Figura 3 apresenta individualmente o valor absoluto de $\log b$ para cada tipo de contingência por bloco de tentativas durante a aquisição da linha de base. Podemos 
observar que, de maneira geral, os participantes apresentaram um menor viés durante as discriminações treinadas com a contingência de Ganhar/Perder (com exceção apenas do participante P6) e que seis dos 12 participantes (P8, P9, P10, P11, P12 e P13) apresentaram um maior viés durante as discriminações condicionais treinadas utilizando a contingência Ganhar/Manter.

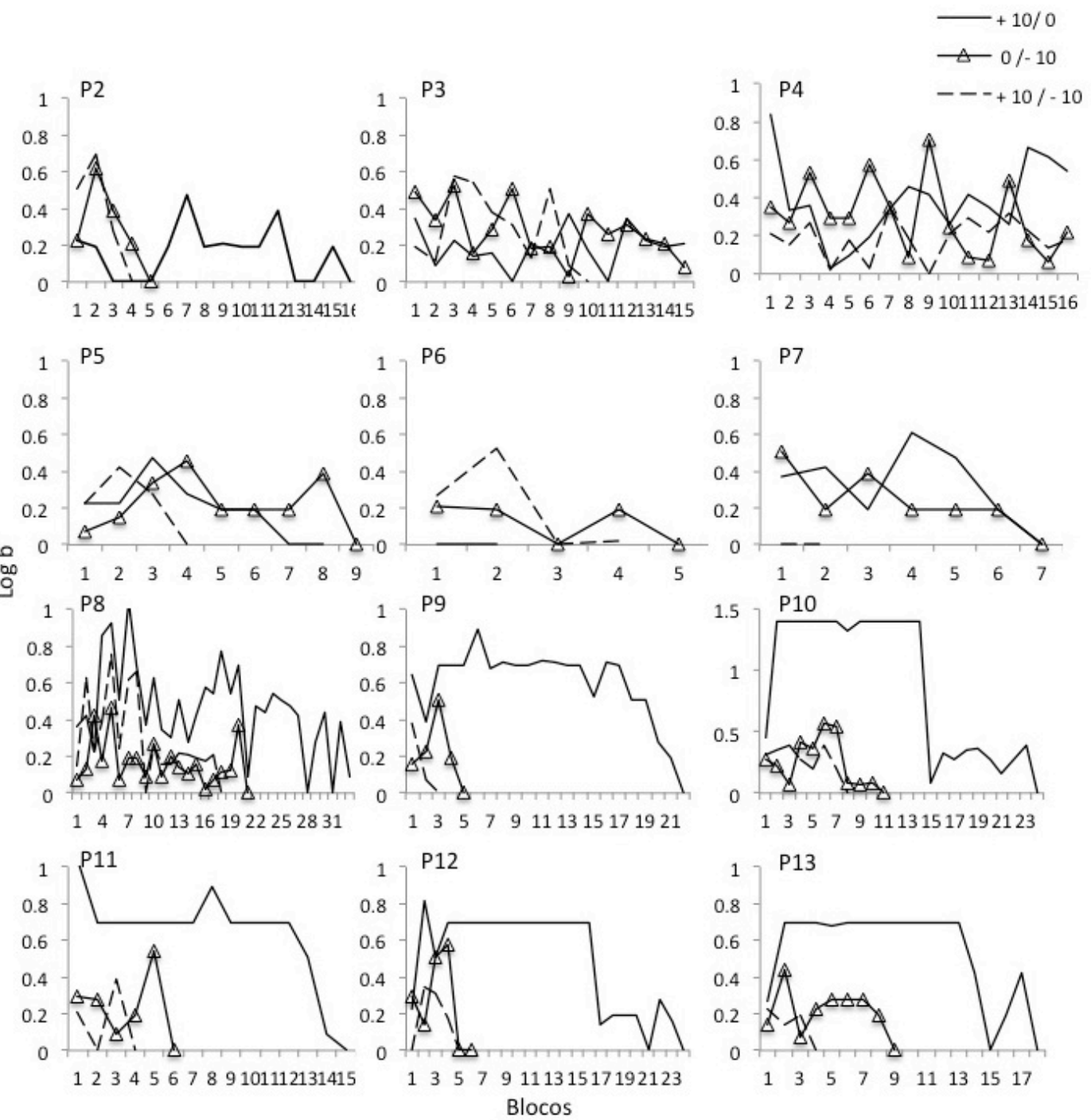

Figura 3. Valor absoluto do log b por tipo de contingência utilizada por bloco de tentativas no treino das discriminações condicionais para cada participante. Notase a diferença no eixo y para o participante P10. 
Durante a fase de linha de base, apenas dois participantes não alcançaram o critério (P4 e P8). No entanto, na fase de revisão da linha de base, dos dez participantes apenas cinco (P2, P5, P6, P7 e P9) alcançaram o critério durante o tempo de realização do experimento (máximo de duas sessões de 45 min cada) e foram submetidos aos testes de equivalência. Todos os participantes submetidos à situação de teste apresentaram $100 \%$ de desempenho condizente nos teste de formação de classes de equivalência.

De maneira geral, o fato de os participantes terem aprendido a responder corretamente nas discriminações condicionais em todos os arranjos das contingências mostra que o ganho e a perda de pontos funcionaram como reforçadores e punidores, respectivamente. Este dado replica os obtidos por Lie e Alsop (2009), Magoon e Critchfield (2008) e Rasmussen e Newland (2008), além de reforçar a possibilidade de uso de pontos em pesquisas com participantes humanos como uma ferramenta útil para avaliar o efeito das manipulações do tipo de reforçamento. Adicionalmente, o presente experimento, assim como o experimento de Lie e Alsop, utilizou um procedimento de discriminação condicional, expandindo assim a possibilidade de investigação dos efeitos de diferentes tipos de reforçamento para além de seus efeitos em uma situação de escolha simples.

O maior viés e o número de tentativas necessárias para aprender as discriminações condicionais durante as tentativas de Ganhar/Manter, demonstrado pela maioria dos participantes (Figura 1, gráfico superior e inferior, e Figura 2), mostra que, de maneira geral, os participantes primeiramente aprenderam a escolher o comparação correto, evitando a perda de pontos nas tentativas de Manter/Perder e, muita das vezes nas tentativas de Ganhar/Manter, permaneciam escolhendo um comparação incorreto por produzir a manutenção (0), mesmo tendo a possibilidade de ganhar pontos. O presente 
experimento sugere, portanto, que perder pontos como um evento aversivo afasta a escolha do estímulo incorreto mais fortemente do que o ganho de pontos como um reforço positivo atrai a escolha para o estímulo que o produz.

Estes dados, de maneira geral, replicam parcialmente a assimetria entre reforço e punição obtida em uma situação de escolha simples concorrente (Rasmussen \& Newland, 2008) em um procedimento de discriminação condicional, e são consistentes com a hipótese do impacto diferencial de que o reforço negativo controla o responder mais fortemente que o positivo, apresentada pela literatura de tomada de decisão de (e.g. Kahneman \& Tversky, 1979; Baumeister et al., 2001). No entanto, como apontado por Magoon e Critchfield (2008), por razões metodológicas, a presente conclusão deve ser tomada com cautela. Uma discussão pontual sobre alguns dos argumentos a serem considerados neste tipo de experimento será realizada posteriormente.

Como mencionado, apenas cinco dos 12 participantes alcançaram o critério de desempenho durante a linha de base e revisão de linha de base e foram submetidos aos testes de formação de classes de equivalência. Acreditamos que o número reduzido de participantes (apenas 41\%) que alcançaram o critério durante as etapas de treino se deva ao viés na escolha produzido pela combinação dos arranjos das contingências planejados (três tipos de arranjos), fazendo com que o os participantes extrapolassem o tempo máximo delimitado para duração da tarefa (duas sessões de 45 minutos cada).

No entanto, observamos que todos os participantes que passaram para a fase de teste apresentaram um desempenho de $100 \%$ de acerto em todas as tentativas de teste, independentemente da condição de treino utilizada. Este resultado demonstra que a formação de classes de equivalência é possível a partir de discriminações condicionais 
treinadas utilizando uma contingência de reforçamento negativo como, por exemplo, a contingência de Manter/Perder.

No que diz respeito à indiferença durante os testes de formação de classes em função dos arranjos das contingências de treino programadas, uma primeira conclusão seria de que a formação de classes de equivalência não é afetada diferencialmente pelos arranjos de contingências (reforço positivo vs. negativo) da mesma maneira que a distribuição da resposta. No entanto, o fato de que não tenha sido observada nenhuma variabilidade nos testes nos leva a considerar a possibilidade de que os resultados se devam a um efeito de teto, resultante da facilidade de formação das classes treinadas neste experimento.

Uma característica que tem se demonstrado relevante para os resultados de formação de classes de equivalência é o arranjo ou sequência dos estímulos durante a aquisição das relações condicionais - estrutura de treino (e.g., Arntzen, Grondahl, \& Eilifsen, 2010; Arntzen \& Holth, 1997; 2000a; Fields, Adams, \& Verhave, 1993).

A estrutura de treino pode ser organizada de, pelo menos, três maneiras: 1) linear (LS), na qual os elementos estão relacionados sequencialmente por um ou mais elos em comum (e.g. treino $\mathrm{AB} \mathrm{BC})$; 2) many-to-one (MTO), na qual mais de um conjunto de estímulos está relacionado a um único conjunto, este último funcionando como elo das classes (e.g. treino AB CB); e 3) one-to-many (OTM), na qual um conjunto de estímulos está relacionado a mais de um conjunto, neste caso, o primeiro funciona como elo para as classes de equivalência (e.g. treino $\mathrm{AB} A C$; ver revisão de de Rose, Kato, Thé, \& Kledaras, 1997; Fields \& Verhave, 1987; Saunders \& Green, 1999).

Apesar da existência de certa divergência nos resultados ao comparar as estruturas de MTO e OTM, a maioria dos dados corrobora a conclusão de que a estrutura de treino 
LS é a que produz o pior desempenho de formação de classes de equivalência, em relação às demais estruturas (ver introdução de Arntzen, et al., 2010; Saunders \& Green, 1999). Fields e Verhave (1987) apontam que a variável que determina essa dificuldade é o número de elos (tamanho das classes ou distância associativa) existentes durante o treino.

Com o objetivo de comparar o efeito do aumento do tamanho das classes nas diferentes estruturas, Arntzen, et al. (2010) realizaram um experimento no qual participantes humanos foram submetidos ao treino de relações condicionais utilizando as diferentes estruturas de treino (LS, MTO e OTM). Cada estrutura de treino foi utilizada para o estabelecimento de dois conjuntos de discriminações condicionais: a primeira correspondia ao treino de três classes com três membros cada (e.g. treino LS A1B1, A2B2 e A3B3) e a outra ao treino de três classes com quatro membros cada (e.g. treino LS A1B1, A2B2 A3B3 e A4B4). No que diz respeito à estrutura de treino LS, os resultados confirmam as afirmações feitas por Fields e Verhave (1987) e Fields et al. (1993) de que, quanto maior o tamanho das classes, ou o número de elos, menor a probabilidade de formação de classes.

O presente experimento utilizou um delineamento linear no qual, para cada arranjo das contingências, foram treinadas apenas duas classes com três membros cada (i.e. um nódulo). Sendo assim, ao considerarmos os dados obtidos durante os testes de formação de classes neste estudo e avaliarmos a literatura sobre o efeito da estrutura de treino, e mais especificamente do tamanho das classes na formação de classes de equivalência, levantamos a hipótese de que a indiferença nos resultados obtidos durante os testes de formação de classes em função das contingências de reforçamento (reforço positivo vs. negativo) se deva a um efeito de teto, e não a uma característica do fenômeno de formação de classes. 
Com o intuito de testar a hipótese de efeito de teto e, consequentemente, de permitir a avaliação do efeito de diferentes contingências de reforço (positivo vs. negativo) na formação de classes de equivalência, foi planejado o Experimento II.

\section{EXPERIMENTO II}

O presente experimento teve como principal objetivo testar a hipótese de ocorrência de efeito de teto no Experimento I e avaliar apropriadamente o efeito de diferentes contingências de reforço (positivo vs. negativo) na formação de classes de equivalência. Para isso, o procedimento utilizado no Experimento I foi parcialmente replicado, aumentando-se, porém, o tamanho das classes treinadas. Ao invés de treinar classes com três membros $(\mathrm{AB} B \mathrm{~B})$ foram treinadas classes com quatro membros $(\mathrm{AB}$ $\mathrm{BC}$ CD).

Neste experimento, para manter o mesmo número de relações condicionais treinadas durante o experimento I (12 relações condicionais), foram utilizados apenas os dois arranjos das contingências de reforço considerados críticos para o presente objetivo: o de reforço positivo (Ganhar/Manter) e o de reforço negativo (Manter/Perder).

\section{MÉTODO}

Participantes

Participaram do experimento sete adultos com desenvolvimento típico, estudantes universitários, recrutados na Universidade de São Paulo, por meio de 
cartazes e contatos pessoais. A participação no experimento e a aprovação ética foram idênticas às do Experimento I.

\section{Equipamentos e materiais}

Iguais ao Experimento I.

\section{Estímulos}

Neste experimento, foram utilizados apenas os estímulos A1, A2, A3, A4, B1, B2, B3, B4, C1, C2, C3, C4, D1, D2, D3 e D4 (Ver Tabela 1). Como consequências foram utilizados os mesmos estímulos do Experimento I.

\section{Procedimento}

O procedimento foi similar ao utilizado no Experimento I. Contudo, neste experimento foram treinadas as relações condicionais [(A1B1, A2B2); (B1C1, B2C2); (C1D1, C2D2); (A3B3, A4B4); (B3C3, B4C4); (C3D3, C4D4)], sendo seis de cada relação condicional treinada, e utilizados apenas dois arranjos das contingências de reforçamento: 1) $\mathrm{O}$ arranjo de reforçamento positivo, (condição Ganhar/Manter); 2) O arranjo de reforçamento negativo (condição Manter/Perder).

As relações condicionais $\mathrm{A} 1 \mathrm{~B} 1, \mathrm{~B} 1 \mathrm{C} 1, \mathrm{~A} 2 \mathrm{~B} 2, \mathrm{~B} 2 \mathrm{C} 2, \mathrm{C} 1 \mathrm{D} 1$ e $\mathrm{C} 2 \mathrm{D} 2$ foram treinadas utilizando-se o arranjo Ganhar/Manter, as relações A3B3 B3C3, A4B4, B4C4, C3D3 e C4D4 (Ver Tabela 3). Neste experimento, pois, foram utilizados blocos de tentativas com 72 tentativas, sendo 36 de cada condição de treino ou arranjo das contingências. 
Tabela 3. Arranjo das consequências por relação condicional treinada no Experimento II.

\begin{tabular}{|c|c|c|c|}
\hline \multirow{3}{*}{ Arranjo } & \multirow{3}{*}{ Relações treinadas } & \multicolumn{2}{|c|}{ Consequências } \\
\hline & & \multicolumn{2}{|c|}{ programadas } \\
\hline & & $\mathrm{S}+$ & S- \\
\hline \multirow{3}{*}{ Ganhar/Manter } & A1B1, B1C1, C1D1 & \multirow{3}{*}{+10} & \multirow{3}{*}{0} \\
\hline & & & \\
\hline & $\mathrm{A} 2 \mathrm{~B} 2, \mathrm{~B} 2 \mathrm{C} 2, \mathrm{C} 2 \mathrm{D} 2$ & & \\
\hline \multirow{3}{*}{ Manter/Perder } & $\mathrm{A} 3 \mathrm{~B} 3, \mathrm{~B} 3 \mathrm{C} 3, \mathrm{C} 3 \mathrm{D} 3$ & \multirow{3}{*}{0} & \multirow{3}{*}{-10} \\
\hline & & & \\
\hline & A4B4, B4C4, C4D4 & & \\
\hline
\end{tabular}

Neste experimento, o critério de desempenho foi de que o participante acertasse pelo menos 34 das 36 tentativas de cada tipo de contingência em um bloco $(94 \%$ de acertos). O teste de formação de classes de equivalência foi realizado em blocos de tentativas. Primeiramente os participantes foram apresentados a um bloco com 72 tentativas de simetria da transitividade com dois e um nódulo (seis de cada tipo - D1A1, D2A2, D3A3, D4A4, C1A1, C2A2, C3A3, C4A4, D1B1, D2B2, D3B3 e D4B4), seguido de um bloco com 96 tentativas dos demais testes (quatro de cada tipo de teste Simetria: B1A1, B2A2, C1B1, C2B2, B3A3, B4A4, C3B3, C4B4, D1C1, D2C2, D3C3 e D4C4; Transitividade com um nódulo: A1C1, A2C2, A3C3, A4C4, B1D1, B2D2, B3D3, B4D4; Transitividade com dois nódulos: A1D1, A2D2, A3D3, A4D4).

O presente estudo considerou condizente com a demonstração de alguma das propriedades de formação de classes de equivalência, quando os participantes apresentaram o desempenho de $75 \%$ de acerto, ou mais, nas tentativas de um mesmo tipo. 


\section{Medidas}

As mesmas do Experimento I.

\section{RESULTADOS E DISCUSSÃO}

Os participantes realizaram em média 696 tentativas para completar o experimento $(S E M=124.04)$ e $600(S E M=109.42)$ para alcançar o critério durante o estabelecimento da linha de base. Todos os participantes alcançaram o critério de desempenho durante os treinos e foram submetidos aos testes de formação de classes de equivalência.

No gráfico superior da Figura 4, à esquerda, é apresentada a média do número total de tentativas para alcançar o critério de linha de base em cada tipo de contingência para todos os participantes, e à direita encontra-se o número médio para cada participante. Podemos observar que, de maneira geral, os participantes precisaram em média de um número ligeiramente maior de tentativas para alcançar o critério nas discriminações treinadas utilizando-se a contingência Ganhar/Manter $(M=313$; $S E M=74,58)$, em relação às treinadas utilizando-se Manter/Perder $(M=287.14$; $S E M=45.69$ ). No entanto, devido à grande variabilidade entre os participantes, uma comparação entre a médias, empregando-se um teste $t$ pareado, sugere que esta diferença não é significativa $\left(\mathrm{t}_{(6)}=.448 \mathrm{e} \mathrm{p}=.067\right)$.

Nos dados individuais (gráfico superior direito, Figura 4), observamos que três dos sete participantes (P2, P3 e P7) necessitaram de um maior número de tentativas para alcançar o critério nas tentativas da condição Ganhar/Manter, em relação às tentativas de Manter/Perder; e três participantes (P1, P4 e P6) precisaram de um maior número de tentativas durante a condição Manter/Perder em relação a Ganhar/Manter; o participante 
P5 precisou do mesmo número de tentativas para alcançar o critério em ambas as condições.

O gráfico central da Figura 4 mostra, à esquerda, a média do $\log d$ nos três primeiros blocos de tentativas por tipo de contingência e à direita mostra os dados individuais. De maneira geral, podemos observar que o desempenho médio foi superior para a contingência Ganhar/Manter $(M=0,54 ; S E M=0,16)$ do que para a contingência Manter/Perder $(M=0,25 ; S E M=0,08)$. Uma comparação entre as médias (teste $\mathrm{T}$ pareado) aponta uma diferença marginal ente as condições de treino $\left(\mathrm{t}_{(6)}=2.425\right.$, $\mathrm{p}=.052)$.

Os dados individuais (gráfico central direito, Figura 4) corroboram esta diferença. Cinco dos sete participantes (P1, P4, P5, P6 e P7) apresentaram um maior desempenho médio para as tentativas da condição Ganhar/Manter. Os participantes P2 e P3 apresentaram um desempenho médio melhor para as tentativas da condição Manter/Perder.

O gráfico inferior da Figura 4 mostra, à esquerda, a média do valor absoluto de $\log b$ nos três primeiros blocos de tentativas para cada tipo de contingência e, à direita, os dados individuais. É possível observar que as discriminações treinadas utilizando a contingência Ganhar/Manter apresentavam um viés maior $(M=0,50 ; S E M=0,14)$ do que as contingências de Manter/Perder $(M=0,29 ; S E M=0,029)$. No entanto, esta diferença não foi significativa $\left(\mathrm{t}_{(6)}=1.439, \mathrm{p}=.200\right.$ ). Nos dados individuais (gráfico inferior direito, Figura 4), podemos observar que quatro dos sete participantes (P2, P3, P4 e P5) apresentaram um maior viés médio para as tentativas da condição Ganhar/Manter em relação à condição Manter/Perder; dois participantes (P1 e P6) 
apresentaram um viés médio maior para as tentativas de Manter/Perder em relação às de Ganhar/Manter. O participante P7 apresentou o mesmo viés em ambas as condições.
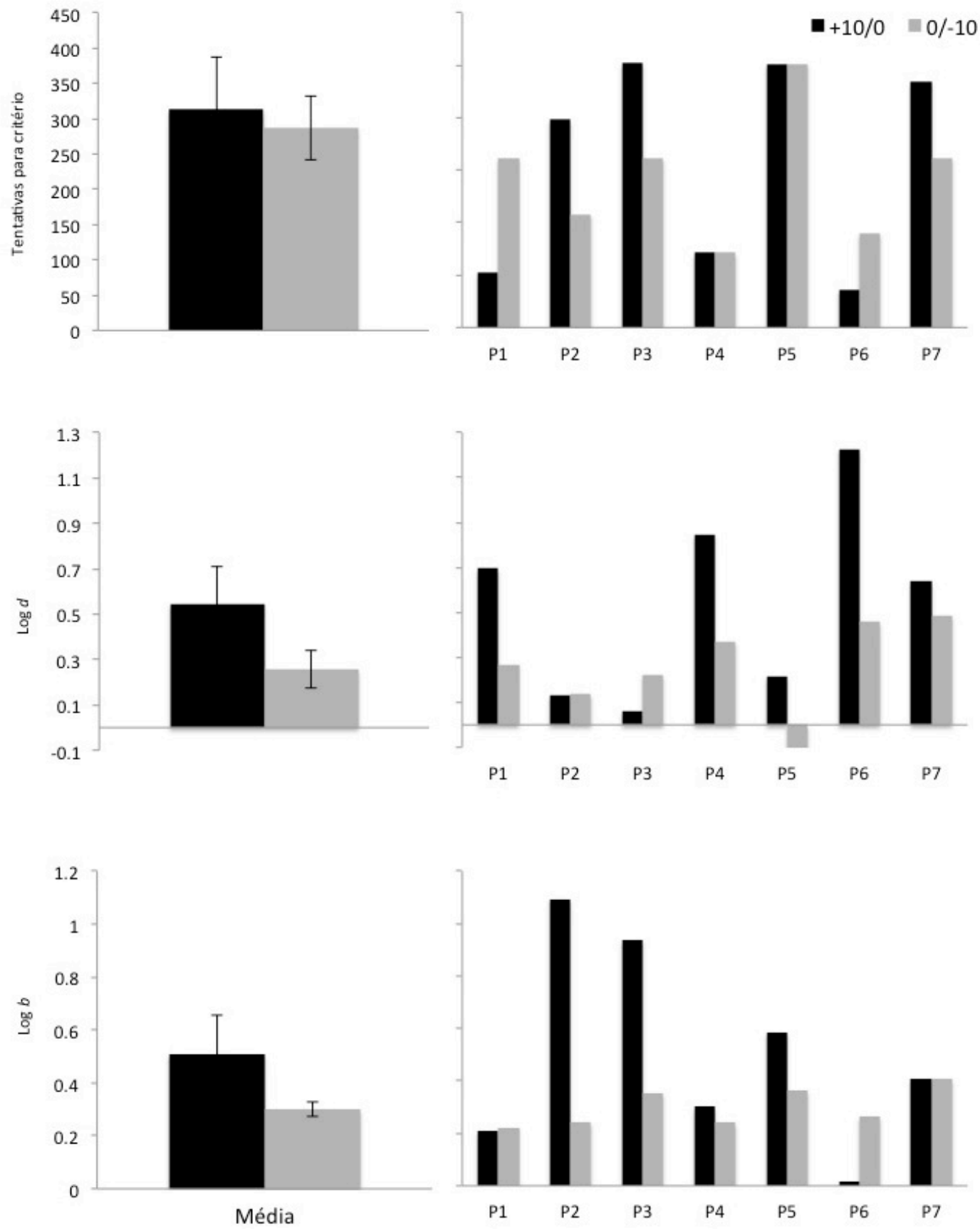

Figura 4. Gráfico superior: Média de tentativas para alcançar o critério de linha de base por tipo de contingência utilizada no treino e por participante; Gráfico central: Média de $\log d$ nos três primeiros blocos por tipo de contingência utilizada no treino; Gráfico inferior: Média do valor absoluto de $\log b$ nos três primeiros blocos por tipo de contingência utilizada no treino. Em todos os gráficos à esquerda são apresentados os dados agrupados para todos os participantes por condição e, à direita, os dados individuais. 
Na coluna à esquerda da Figura 5, são apresentados os desempenhos $(\log d)$ ao longo dos blocos de tentativas de discriminações condicionais da linha de base, para cada tipo de contingência, por participante. No que diz respeito à sequência de aquisição das discriminações condicionais, podemos observar que dois dos sete participantes (P1 e P6) aprenderam primeiramente as discriminações condicionais treinadas a partir da contingência Ganhar/Manter; três (P2, P3 e P7) aprenderam primeiro as discriminações treinadas pela contingência Manter/Perder; e dois (P4 e P5) aprenderam os dois conjuntos discriminações no mesmo bloco.

No que diz respeito ao desempenho dos participantes, podemos observar que os participantes que aprenderam primeiramente as discriminações treinadas pela contingência de Ganhar/Manter (P1 e P6) apresentaram, desde o começo do treino, um desempenho mais acurado nestas discriminações do que nas treinadas com a contingência de Manter/Perder. Todavia, dois dos três participantes que aprenderam primeiramente as discriminações treinadas pela contingência Manter/Perder (P2 e P3) iniciaram o experimento (primeiro bloco) com um desempenho ligeiramente melhor nas tentativas da condição Ganhar/Manter, e esse desempenho foi revertido a partir do segundo bloco de tentativas. O participante $\mathrm{P} 7$, apesar de aprender primeiramente as discriminações da condição Manter/Perder, apresentou o mesmo desempenho para ambos os conjuntos de discriminações no início do treino (ver Figura 5).

Como exceção aos padrões descritos anteriormente, apesar de o participante P4 ter alcançado o critério de desempenho no mesmo bloco para ambas as contingências de treino, durante todo o treino, apresentou um desempenho superior nas discriminações condicionais treinadas pela contingência de Ganhar/Manter em relação às treinadas pela 
contingência Manter/Perder. O participante P5 não apresentou nenhuma diferença no desempenho durante a aquisição das discriminações condicionais (ver Figura 5).

$\mathrm{Na}$ coluna à direita da Figura 5, são apresentados os valores absolutos da medida de viés $(\log b)$ ao longo dos blocos de tentativas de discriminações condicionais da linha de base, para cada tipo de contingência, por participante. Podemos observar que três dos sete participantes (P1, P4 e P6) apresentaram um viés baixo para ambas as condições de treino, com um valor de $\log b$ variando entre 0 e 0.5 , e que outros três participantes (P2, P3 e P7) apresentaram um maior viés durante as discriminações treinadas com a contingência Ganhar/Manter em relação às discriminações treinadas pela contingência de Manter/Perder. O participante P5 não apresentou diferenças marcantes no viés entre as condições de treino ao longo dos blocos de tentativas.

Podemos observar que, de maneira geral os participantes que aprenderam primeiramente as discriminações treinadas com as contingências de Manter/Perder (P2, P3 e P7) apresentaram um viés maior nas tentativas da condição Ganhar/Manter do que nas tentativas da condição Manter/Perder, ao longo do treino. 

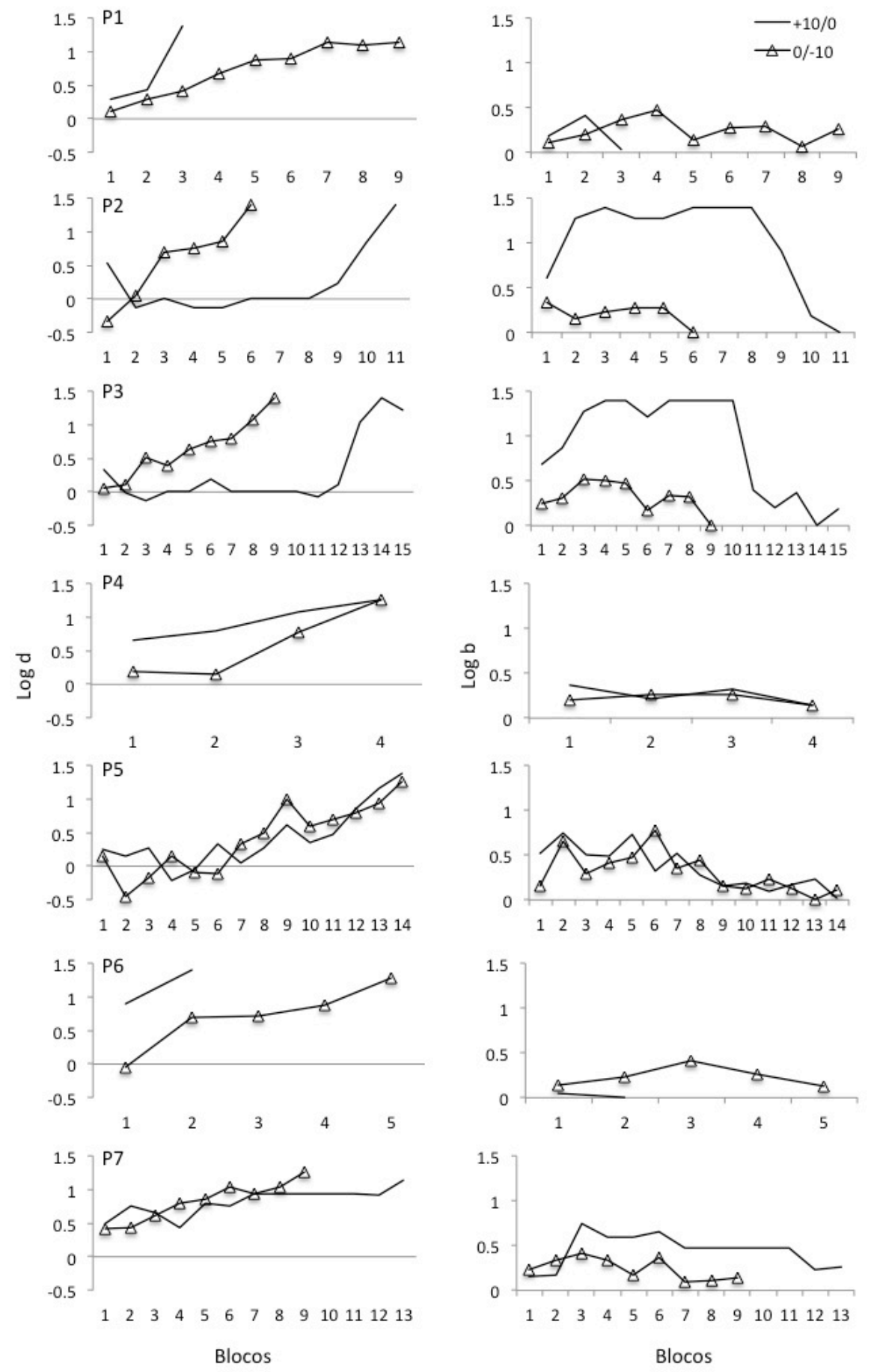

Figura 5. Gráficos na coluna à esquerda: $\log d$ por tipo de contingência utilizada por bloco de tentativas no treino das discriminações condicionais para cada participante; Gráficos na coluna à direita: $\log b$ por tipo de contingência utilizada por bloco de tentativas no treino das discriminações condicionais para cada participante. 
Como mencionado anteriormente, neste experimento todos os participantes alcançaram o critério de desempenho, no qual tinham que acertar pelo menos 34 das 36 tentativas de uma mesma condição de treino em um bloco, durante a linha de base e revisão de linha de base; e foram submetidos aos blocos de teste de formação de classes de equivalência (total de 168 tentativas de teste, 84 de cada uma das condições de treino).

Na Figura 6, gráfico à esquerda, podemos observar que o número de acertos nos testes foi maior para as tentativas da condição Ganhar/Manter $(M=72.57$; SEM=2.99) do que durante as tentativas da condição Manter/Perder $(M=54.71 ; S E M=8.78)$, diferença evidenciada de maneira marginal por um teste $\mathrm{T}$ pareado $\left(\mathrm{t}_{(6)}=2.395 \mathrm{e}\right.$ $\mathrm{p}=0.054)$.

Quatro dos sete participantes (P1, P4, P5, P6) apresentaram um maior número de acertos nas tentativas de teste da condição Ganhar/Manter do que nas tentativas da condição Manter/Perder; dois participantes (P2 e P7) apresentaram um número maior de acertos nas tentativas de testes da condição Manter/Perder e o participante P3 apresentou o mesmo número de acertos nas tentativas de ambas as condições (Ver gráfico à direita da Figura 6). 


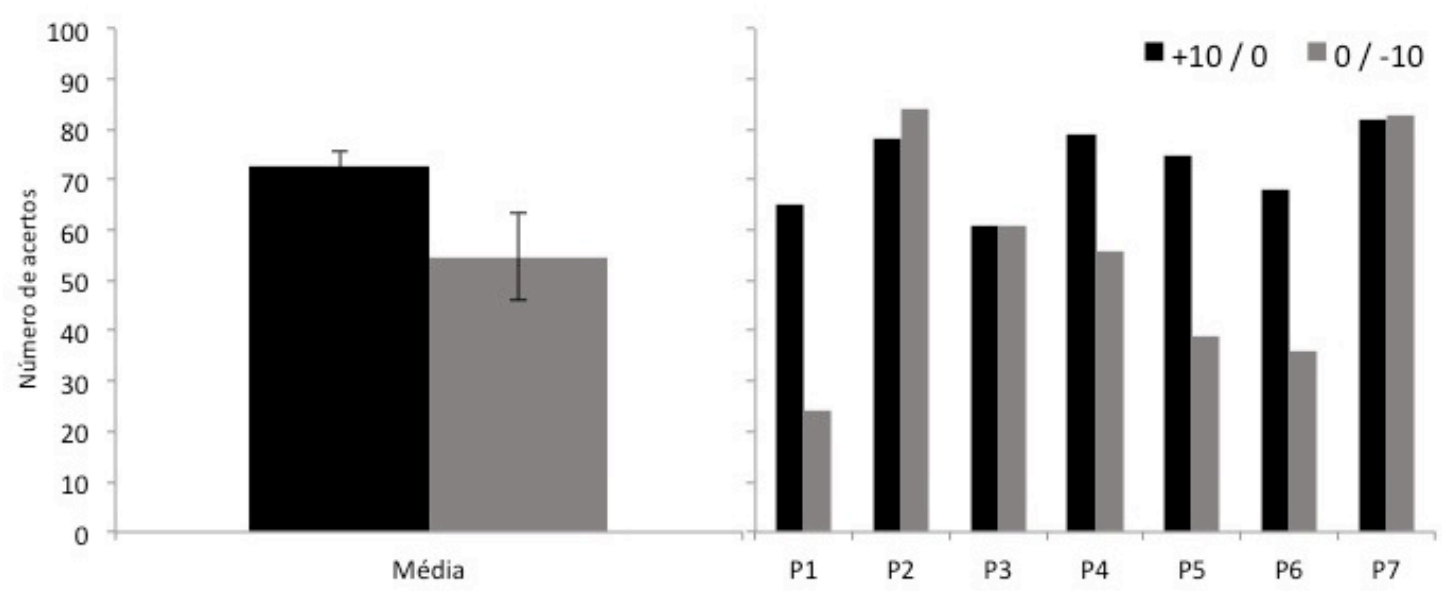

Figura 6. Gráfico à esquerda: Média de acertos durante os testes de formação de classes de equivalência por condição de treino; Gráfico à direita: Número total de acertos durante os testes de formação de classes de equivalência para cada participante por condição de treino.

$\mathrm{Na}$ Figura 7, é apresentada a média das porcentagens de acerto nos testes de formação de classes de equivalência por tipo de teste e distância nodal. São apresentados os testes de equivalência com dois e um nódulo (Equiv 2 e Equiv 1, respectivamente), testes de transitividade com dois e um nódulo (Trans 2 e Trans 1, respectivamente) e testes de simetria (Sim), para todos os participantes.

Podemos observar que, descritivamente, o desempenho nos testes de formação de classe foi superior para as tentativas de teste da condição de Ganhar/Manter do que para as condição Manter/Perder, podemos, porém, observar uma grande variabilidade individual no desempenho durante os testes da condição Manter/Perder. Uma comparação entre as médias das porcentagens de acerto entre as condições de treino para cada tipo de teste, utilizando teste $\mathrm{T}$ pareado, indicou que as diferenças não são significativas $(p>.05$; Ver Figura 7$)$. 


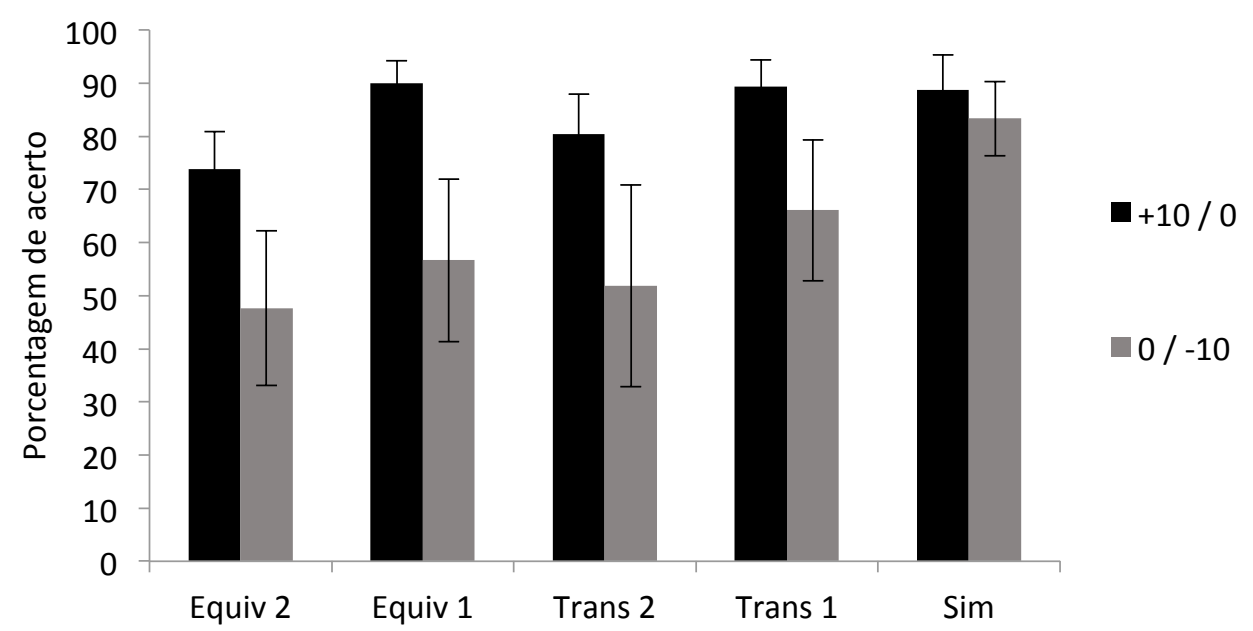

Figura 7. Porcentagem média para cada tipo de teste de formação de classes durante o Experimento II.

Na Figura 8, são apresentadas as porcentagens de acerto durante os tipos de teste, utilizando gráficos similares ao da Figura 7, porém com os dados de cada participante.

Durante os testes de equivalência com um e dois nódulos, quatro dos sete participantes (P1, P4, P5 e P6) apresentaram um desempenho condizente com a formação de classes de equivalência nas tentativas da condição Ganhar/Manter, porém, apresentaram um desempenho de $50 \%$ de acerto ou menos nas tentativas da condição Manter/Perder (Ver Figura 8).

O participante P2 apresentou um desempenho ao acaso nas tentativas de teste de equivalência com dois nódulos para condição Ganhar/Manter, um desempenho condizente com a formação de classes de equivalência nas tentativas da condição Manter/Pender e 100\% de acerto nas tentativas de equivalência com um nódulo para ambas as condições de treino. O Participante P3 respondeu ao acaso nas tentativas de equivalência com dois nódulos e de maneira condizente com a formação de classes (75\% de acerto, ou mais) nas tentativas de equivalência com um nódulo para ambas as condições de treino (Ver Figura 8). 
Nas tentativas de teste de transitividade, os participantes P1, P5 e P6 apresentaram um desempenho condizente com a formação de classes de equivalência para as tentativas da condição Ganhar/Manter, porém, nas tentativas da condição Manter/Perder erraram, todas as tentativas de teste de transitividade com dois nódulos e apresentaram um desempenho de $50 \%$ de acerto ou menos nas tentativas de transitividade com um nódulo. Os participantes P2, P4 e P7, apresentaram um desempenho de 100\% de acerto em todas as tentativas de teste de transitividade em ambas as condições (Ver Figura 8).

O participante $\mathrm{P} 3$ apresentou um desempenho ao acaso na tentativas de transitividade com dois nódulos, para ambas as condições de treino. No entanto, durante as tentativas de teste de transitividade de um nódulo, apresentou um desempenho condizente com a formação de classes $(75 \%$ de acerto) para as tentativas da condição Ganhar/Manter e ao acaso para as tentativas da condição Manter/Perder (Ver Figura 8).

De maneira geral, podemos observar que todos os participantes apresentaram um desempenho superior a $60 \%$ de acerto nas tentativas de simetria, para ambas as condições. O participante P7 apresentou um desempenho condizente com a formação de classes de equivalência em todos os testes para ambas as condições de treino (Ver Figura 8). A opção por apresentar os resultados dos testes de formação de agrupados por tipo de teste foi feita por consideramos que era representativa dos dados separados. Para uma apresentação mais detalhada dos dados, ver Figura 9 e 10 nos Anexos II e III, respectivamente. 

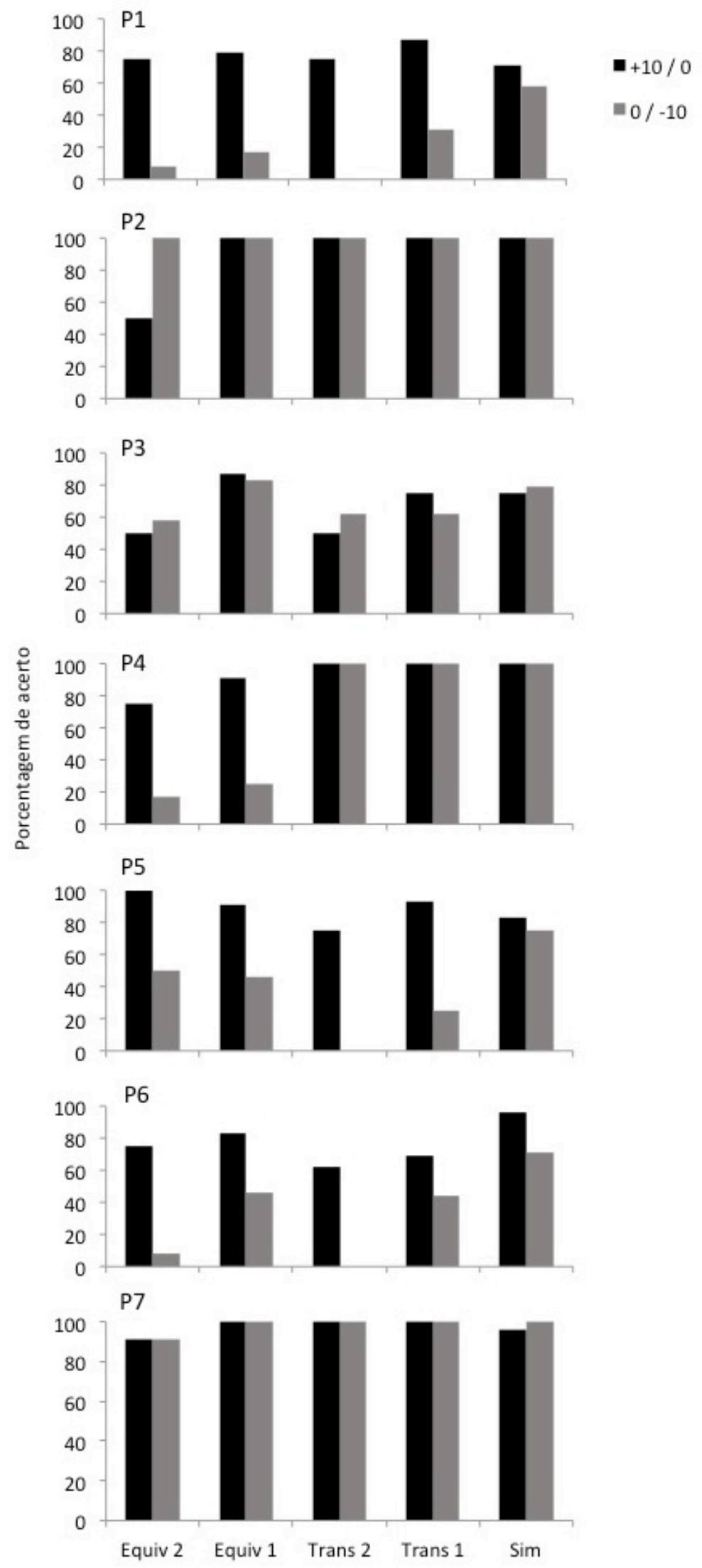

Figura 8. Porcentagem de acertos para cada tipo de teste de formação de classes de equivalência por participante. 
No que diz respeito ao efeito das diferentes contingências de reforço na aquisição das discriminações condicionais, neste experimento podemos observar que o número de tentativas para alcançar o critério de linha de base foi maior para condição Ganhar/Manter (ver gráfico superior esquerdo da Figura 4), como observado no Experimento I (gráfico superior esquerdo da Figura 1).

Este resultado pode ser explicado pelo fato de que, no presente experimento, não existiu uma terceira contingência mista (Ganhar/Perder) com um terceiro conjunto de discriminações condicionais a serem aprendidas. Em razão disto, de maneira geral, os participantes tiveram mais facilidade em distinguir entre as contingências de reforço e de punição envolvidas nas relações a serem aprendidas. Esta explicação é corroborada quando observamos que o desempenho $(\log d)$ nos três primeiros blocos de tentativas foi ligeiramente superior para as discriminações da condição Ganhar/Manter do que para as de Manter/Perder (ver gráfico central à esquerda da Figura 4). Da mesma maneira que a diferença no número de tentativas para alcançar o critério de linha de base, essa diferença não foi observada entre as mesmas condições no Experimento I (ver gráfico central à esquerda da Figura 1).

Quando analisamos o viés $(\log b)$ produzido durante os primeiros três blocos de tentativas, descritivamente, podemos observar um viés maior durante os primeiros blocos de tentativas na condição Ganhar/Perder (gráfico inferior à esquerda da Figura 4). Devido à grande variabilidade observada entre os participantes, esta diferença não foi considerada estatisticamente significativa. Todavia, quando analisamos os dados individuais podemos observar uma tendência na produção de um viés mais acentuado nas tentativas da condição Ganhar/Manter em relação à condição de Manter/Perder. 
Individualmente (gráfico inferior à direita da Figura 4), observamos que a maioria dos participantes (quatro de sete) apresentou um maior viés na condição Ganhar/Manter durante os três primeiros blocos de tentativas. Adicionalmente, ao analisar os dados individuais ao longo de todo o treino (coluna à direita da Figura 5), observamos que três dos sete participantes apresentaram um maior viés para as tentativas de treino da condição Ganhar/Manter do que para a condição Manter/Perder.

A tendência à produção de um viés por estímulo nas tentativas da condição de Ganhar/Manter replica, parcialmente, os dados obtidos no Experimento I e sugere um impacto diferencial das contingências de reforço negativo e positivo. Isto corrobora os resultados obtidos por Rasmusen e Newland (2008), em experimentos de escolha simples, além de estar em consonância com a literatura de tomada de decisão (e.g. Baumeister et al., 2001). Contudo, a grande variabilidade observada durante a aquisição das discriminações condicionais aponta a necessidade de realização de experimentos que investiguem, mais especificamente, possíveis fontes de variabilidade que podem ter afetado os resultados.

O resultados do efeito dos diferentes tipos de contingências de reforço na formação de classes de equivalência apontam: a) a possibilidade de formação de classes a partir de uma contingência de reforço negativo (e.g. Manter/Perder), replicando os dados do Experimento I; b) que o tipo de reforçamento (reforço negativo vs. negativo), empregado durante a aquisição das discriminações condicionais, afeta diferencialmente a probabilidade de formação de classes de equivalência. Mais especificamente, indica que o uso de uma contingência de reforço negativo (Manter/Perder) diminui a probabilidade de formação de classes, produzindo um maior número de erros (ver Figura 6) do que quando do emprego de uma contingência de reforçamento positivo 
(Ganhar/Manter), confirmando a hipótese de ocorrência de efeito de teto durante os testes no Experimento I.

Da mesma maneira que para o viés produzido durante a aquisição, nos testes de formação de classes podemos observar uma grande variedade entre os participantes, principalmente para as tentativas da condição de reforço negativo (Manter/Perder).

\section{DISCUSSÃO GERAL}

Os dados sobre o efeito das diferentes contingências de reforçamento na formação de classes de equivalência apontam que a formação de classes de equivalência é possível a partir de uma contingência de reforçamento negativo (Experimento I e II). Porém, a probabilidade de formação de classes é diferencialmente afetada pelas contingências de reforço positivo e negativo, sendo menos provável quando as discriminações são treinadas utilizando-se uma contingência de reforçamento negativo do que quando utilizada uma contingência de reforço positivo (Experimento II).

A sequência na qual as discriminações foram aprendidas (Experimento I) e o viés inicial observado para as tentativas da condição de reforço positivo (Ganhar/Manter Experimento I e II) sugerem que o reforço positivo e a punição (neste caso vinculada a uma contingência de reforço negativo) são assimétricos no controle da resposta, pelo menos em uma etapa inicial do treino, corroborando a hipótese do impacto diferencial obtida por alguns dos estudos de escolha (e.g. Magoon \& Crichfield, 2001; Rasmussen \& Newland, 2008) e pela literatura cognitiva de tomada decisão (e.g. Kahneman \& Tversky, 1979, ver revisão de Baumeister, et al., 2001).

A presente discussão será dividida em três partes: 1) discussão dos resultados obtidos em relação à hipótese do impacto diferencial (reforço positivo vs. negativo); 2) discussão do efeito dos diferentes tipos de arranjo das contingências no controle de 
estímulos estabelecidos e na formação de classes de equivalência e 3) discussão sobre como a proposição de Sidman (2000) sobre a formação de classes de equivalência poderia se ajustar aos dados obtidos a partir da manipulação do tipo de contingências de reforço.

Diferentes arranjos das contingências (reforço positivo e negativo) e o impacto

\section{diferencial}

A maior parte dos estudos relacionados aos efeitos da punição em humanos utiliza ganhos e perdas de pontos como eventos reforçadores e punidores, porém sempre trocáveis por valores em dinheiro (e.g. Bradshaw, Szabadi, \& Bevan, 1979; O’Donnel \& Crosbie, 1998; Magoon \& Critchfield, 2008; Rasmussen \& Newland, 2008). Nos dois experimentos aqui realizados, a aquisição das discriminações condicionais aponta que os ganhos e a perda de pontos podem ser utilizados como reforçadores e punidores, na ausência de dinheiro relacionado à pontuação apresentada. Estes dados replicam os obtidos por Lie e Alsop (2009), sugerindo que o uso de pontos (ganhos e perdas), em experimentos com humanos, pode ser uma ferramenta útil na investigação dos efeitos da punição sobre o responder, em situações simples de escolha (e.g. Bradshaw, et al.,; Magoon \& Critchfield; Rassmusen \& Newland) e também em situações de discriminação condicional (e.g. Lie \& Alsop).

Como mencionado anteriormente, nos Experimento I e II foi observado um viés $(\log b)$ mais acentuado durante a aquisição das discriminações condicionais treinadas pela contingência de reforço positivo (Ganhar/Manter) do que para as treinadas pela contingência de reforço negativo (Manter/Perder - Ver figuras 1 e 4), quando apresentados simultaneamente. Ou seja, nestes experimentos, o viés apresentado durante 
as tentativas com a contingência de reforço positivo significa que uma grande parte dos participantes permaneceu escolhendo um estímulo que produzia a manutenção dos pontos, mesmo tendo a possibilidade de ganhar. Este resultado sugere que, pelo menos em uma fase inicial da aquisição, a perda de pontos afasta o responder mais fortemente do que o reforçamento atrai.

Foi observado que para algumas das medidas utilizadas as diferenças não foram consideradas significativas. Provavelmente, a grande variabilidade observada entre os participantes foi responsável por esta dificuldade. Sendo assim, pretendemos analisar fatores que podem ser responsáveis pela produção desta variabilidade, auxiliem a compreensão do efeito dos tipos de contingências empregados e dos resultados obtidos, bem como apontem características procedimentais consideradas relevantes.

Punição e reforço negativo. Os experimentos aqui realizados utilizaram um procedimento de discriminação condicional com tentativas discretas e optou-se por um procedimento de reforçamento negativo (Manter/Perder), combinado a um de reforço positivo (Ganhar/Manter).

Magoon e Critchfield (2008) apontam que, dado que na literatura analítico comportamental a noção de reforçamento negativo está intimamente ligada à de punição (e.g. Sidman 1989; Skinner, 1953), talvez utilizar uma contingência de reforço negativo não seja a opção mais adequada para avaliar a hipótese do impacto diferencial. Os autores sugerem que, quando empregada uma contingência de reforço negativo, mais de um fenômeno pode estar envolvido: o da punição e o do estabelecimento de valor reforçador por parte do evento que evita a produção do evento aversivo. Magoon e Critchfield se referem a este problema como a comparação "bom versus mal", pois, neste contexto, não somos capazes de determinar o que conta como "bom", o que conta 
como "neutro" ou o que conta como "ruim". Assim, esta possibilidade de que mais de um processo esteja envolvido quando utilizada uma contingência de reforço negativo pode ser uma fonte de variabilidade individual.

Em acordo com esta hipótese está o fato de que na maioria dos experimentos que corroboram a hipótese do impacto diferencial são utilizados procedimentos de punição (e.g. Kahneman \& Tversky, 1979; Rasmussen \& Newland, 2008). No presente experimento, apesar de podermos considerar que a perda de pontos funciona como um punidor da resposta nos elementos incorretos, o fato de o experimento exigir que os participantes possam responder em um evento, evitando o evento punidor (aversivo), faz com que a contingência empregada configure um arranjo de reforço negativo. Futuros experimentos poderiam avaliar, especificamente, como o uso de uma contingência de reforçamento e punição sobrepostos afetam a aquisição de discriminações condicionais.

Grau de aversividade dos estímulos. Outra possível fonte de variabilidade apontada por Magoon e Critchfield (2008) é a variação no valor reforçador e aversivo dos ganhos e perdas de pontos em função das diferenças na história de cada participante. Os pontos são sempre considerados reforçadores secundários ou condicionados (Catania, 1999), e muitos fatores idiossincráticos podem alterar o valor do ganho e da perda de pontos.

Podemos observar que, na maioria dos dados provenientes da literatura cognitiva de tomada de decisão, os experimentos empregam um delineamento de grupos, como por exemplo, os estudos conduzidos por Kahneman e Tversky (1979). Nestes experimentos foram utilizados, no mínimo, 66 participantes em cada condição, consequentemente, foram apresentadas apenas as médias de escolhas. Ou seja, alguns 
dos participantes não apresentaram a escolha de acordo com a hipótese do impacto diferencial.

Assim, podemos imaginar que a mesma fonte de variabilidade poderia estar atuando nos experimentos de tomada de decisão. Contudo, como nos experimentos de orientação analítico comportamental são privilegiados delineamentos de sujeito único com um número de participantes mais reduzido (como o utilizado nos Experimentos I e II), faz-se necessário controlar mais adequadamente essa variabilidade para permitir uma avaliação adequada das variáveis. Portanto, sugerimos que experimentos que tentassem controlar mais adequadamente o valor dos eventos reforçadores condicionados, como por exemplo, uso de ganho e a perda de valores em dinheiro ou a criação de uma história arbitrária mais consistente com outros eventos (e.g. um sistema de fichas - e.g. Hakenberg, 2009), poderiam controlar parte da variabilidade observada.

Tendo em vista que o principal interesse dos experimentos estava relacionado a uma avaliação dos processos envolvidos na aquisição de discriminações condicionais, a exemplo de indícios dos controles de estímulos estabelecidos durante o treino, os procedimentos utilizados no Experimento I e II apresentam algumas diferenças a serem consideradas em relação aos utilizados pela literatura que normalmente avalia o efeito da punição no responder.

Usualmente, os experimentos que avaliam os efeitos da punição no responder utilizam uma tarefa de escolha concorrente simples, manipulam as proporções dos ganhos e perdas de pontos entre as escolhas e avaliam como a distribuição do responder em estado estável se ajusta à Generalized Matching Law (GML - Baum, 1974; ver revisão de Davison \& McCarthy, 1988). A constatação de um viés acentuado em uma condição que envolve uma contingência de reforço negativo ou punição é utilizada 
como indicativo de uma assimetria entre o efeito do reforço e da punição (e.g. Ransmussen \& Newland, 2008; Magoon \& Critchfield, 2008).

A primeira diferença apresentada pelos Experimentos I e II diz respeito ao fato de que ambos estavam interessados na avaliação do viés durante a aquisição das relações condicionais, mais especificamente, durante a etapa inicial do treino (três primeiros blocos de tentativas) e não durante uma condição estável, como normalmente encontrado na literatura (e.g. Critchfield \& Magoon, 2001; Lie \& Alsop, 2008; Magoon \& Critchfield, 2008; Ransmussen \& Newland, 2008).

Outra diferença reside no fato de que os estudos utilizam, pelo menos, três pontos, isto é, diferentes proporções das consequências em um mesmo tipo de contingência (e.g. reforço negativo), e a partir de então estimam o valor de viés como um dos parâmetros da GML (ver Davison \& McCarthy, 1988). Neste sentido, cabe ressaltar que os valores de viés estimados a partir de mais pontos compreendem uma medida mais confiável do resultado dos arranjos específicos das contingências e sua correspondência com o modelo ao qual está sendo comparado (ver Motulsky \& Christopoulis, 2006). Todavia, dado o objetivo de avaliar o estabelecimento das discriminações condicionais e a formação das classes de equivalência, cada arranjo das contingências nestes experimentos possuiu apenas uma distribuição das consequências (o viés estimado corresponde a um ponto de dados).

Experimentos futuros que tenham como objetivo especificamente avaliar o uso de diferentes contingências de reforçamento em uma situação de discriminação condicional, utilizando o procedimento aqui descrito, poderiam realizar a tarefa com diferentes distribuições dos reforçadores e punidores simultaneamente, e a partir de então estimar o viés em função da GML. 
A terceira diferença está no fato de que os experimentos avaliam a produção do viés para a mesma tarefa na qual o arranjo das contingências foi imposto, ou seja, os participantes são submetidos a uma contingência de reforço negativo em uma tarefa de escolha simples e o viés observado está relacionado à mesma tarefa. Nos Experimentos I e II, o viés observado diz respeito ao responder nas discriminações de reforço positivo, mas a produção do viés é considerada resultado do efeito da contingência de reforço negativo. Como já indicado, entendemos que, apesar da diferença, o significado da medida de viés coincide em ambos os casos.

Diferentes arranjos das contingências (reforço positivo e negativo), formação de classes de equivalência e controle de estímulos

Os Experimentos I e II compreendem a primeira demonstração de formação de classes de equivalência a partir de uma contingência de reforço negativo. Adicionalmente, no Experimento II podemos observar que, de maneira geral, a formação de classes de equivalência é menos provável ou mais variável quando utilizada uma contingência de reforço negativo (ver figuras 7 e 8).

A evidência de que a formação de classes de equivalência é possível a partir do uso de uma contingência de reforço negativo nos leva a crer que a afirmação feita por Sidman (2000), sobre os elementos que passam a compor as classes de equivalência, necessita ser ampliada de maneira a permitir prever o que irá ocorrer em uma situação na qual a contingência envolve a produção de eventos aversivos.

O fato de a formação de classes de equivalência ter sido afetada diferencialmente pelos tipos de contingência empregada sugere que o arranjo dos reforçadores ou punidores constitui uma variável relevante na formação de classes de 
equivalência, corroborando inicialmente a proposição de Sidman (2000) sobre a origem operante das classes de equivalente. No entanto, não podemos considerar esses resultados como uma evidência indiscutível da determinação operante das formação de classes de equivalência, pois as formulações que atribuem uma origem de tipo respondente à formação de classes de equivalência também consideram que os eventos correlacionados às escolhas corretas ("apetitivos" ou aversivos) podem afetar a maneira como os estímulos vão passar a controlar o responder (e.g. Tonneau, 2001; Delgado \& Hayes, 2014).

Assim, da mesma maneira que utilizado para explicar parte dos resultados negativos na formação de classes de equivalência com determinadas populações, consideramos mais adequado, ao invés de se referir às definições apresentadas por Sidman (2000) de "pares ordenados" ou "elementos positivos", lidar diretamente com a noção de topografia de controle de estímulos (TCE’s - McIlvane \& Dube, 1992; 2003), e avaliar como a literatura de controle de estímulos pode contribuir para explicar os dados de formação de classes de equivalência a partir de uma contingência de reforço negativo. Esta decisão não denota, necessariamente, uma incompatibilidade das afirmações (e.g. McIlvane, et al. 2000). Não obstante, consideramos que representa a fragilidade das definições apresentadas por Sidman, na medida em que não são especificadas as variáveis relevantes à observação.

Ray e Sidman (1970) sugerem que todo estímulo é complexo no sentido de que tem diferentes propriedades físicas passíveis de controlar o responder. Dube e McIlvane (1996) apontam que, como consequência desta possibilidade, uma mesma resposta pode ser capaz de produzir consistentemente o reforço planejado e, ainda assim, estar sobre controle de propriedades do estímulo diferentes das planejadas pelo experimentador. Dube e McIlvane apontam que, na maioria dos casos, o desempenho 
durante a realização da tarefa discriminada não permite evidenciar qual TCE está controlando o responder, sendo necessários testes adicionais que evidenciem os controles estabelecidos.

Partindo da noção de que diferentes topografias de controle de estímulos podem ser estabelecidas para um mesmo desempenho em uma tarefa discriminativa (e.g. uma discriminação condicional), Carrigan e Sidman (1992) analisam dois possíveis tipos de controle (seleção e rejeição) em uma situação de discriminação condicional com duas comparações, e as consequências deste controle nos resultados dos testes de formação de classes de equivalência.

O controle por seleção é observado quando o desempenho de escolher o comparação correto está sob controle do próprio estímulo a ser escolhido $(\mathrm{S}+)$, e o controle por rejeição é observado quando o desempenho de escolher o comparação correto está sob controle do estímulo incorreto (S-). Por exemplo, durante o treino de uma discriminação condicional (AB) com apenas duas comparações (B1 e B2), quando o desempenho de escolher o comparação B1 e não o B2, na presença do modelo A1, está sob controle do próprio estímulo B1, configura-se uma situação de controle por seleção. No entanto, se a escolha do estímulo B1, na presença do modelo A1, está sob controle do estímulo B2, configura-se uma situação de controle por rejeição (Carrigan \& Sidman, 1992 ou revisão de Perez \& Tomanari, 2008).

É importante destacar que, em ambos os tipos de controle, os participantes apresentam o desempenho de escolher o comparação correto e produzem $100 \%$ dos reforços programados durante a sessão. No entanto, a utilização de diferentes TCE's produziria o aprendizado de relações condicionais diferentes para cada tipo de controle. Como resultado de um controle por seleção seriam aprendidas as relações condicionais 
A1B1 e A2B2. Como resultado de um controle por rejeição seriam aprendidas as relações A1B2 e A2B1 (Carrigan \& Sidman, 1992).

Apesar da existência de diferentes procedimentos para evidenciar o tipo de relação de controle estabelecida durante a aquisição das discriminações (e.g. uso de testes com máscaras, uso de resposta de observação, dentre outros; ver revisão de Perez \& Tomanari, 2013), Carrigan e Sidman (1992) apontam que os resultados nos testes de equivalência podem evidenciar o tipo de controle estabelecido durante a aquisição das discriminações condicionais.

Quando o desempenho nas discriminações condicionais é controlado por seleção, são esperados resultados positivos em todos os testes de formação de classes de equivalência (Simetria, Transitividade e Equivalência). Entretanto, quando o desempenho é controlado por rejeição são esperados resultados positivos em todos os testes de Simetria; resultados negativos nos testes de Transitividade e Equivalência das relações com números impares de nódulos; e resultados positivos nos testes de Transitividade e Equivalência das relações com números pares de nódulos (Carrigan \& Sidman, 1992 ou revisão de Perez \& Tomanari, 2008). Esta afirmação tem sido confirmada pela produção empírica da área (Johnson \& Sidman, 1993; Magnusson, 2002; 2003; Perez 2008). Ademais, alguns experimentos sugerem a possibilidade de que se desenvolvam os dois tipos de controle simultaneamente, o que também geraria um resultado positivo em todos os testes de formação de classes (e.g. Hamasaki, 2009).

Tendo em vista a possibilidade de inferir os controles de estímulos estabelecidos durante as discriminações condicionais a partir dos resultados dos testes de equivalência, no Experimento I, o fato de que todos os participantes submetidos aos 
testes tenham apresentados resultados condizentes com a formação de classes sugere que a contingência de reforçamento negativo pode produzir controle por seleção.

No Experimento II, a maioria dos participantes apresentou um desempenho condizente com a formação de classes com os estímulos da condição de reforço positivo (Ganhar/Manter). Para os estímulos da condição de reforço negativo (Manter/Perder), dois dos sete participantes (P2 e P7) apresentaram resultados positivos nos testes de formação de classes de equivalência, corroborando os dados do Experimento I. Os demais participantes (P1, P3, P4, P5, e P6) apresentaram um desempenho variável durante os testes de formação de classes; porém, nenhum participante apresentou um desempenho típico de controle por rejeição. Os resultados dos Experimentos I e II sugerem que, em uma situação na qual a formação das classes de equivalência é facilitada, a exemplo de quando são treinadas classes com apenas um nódulo (Experimento I), a contingência de reforço negativo pode produzir controle por seleção; no entanto, em uma situação na qual a formação de classes é mais difícil, como quando treinadas classes com dois nódulos (Experimento II), o desenvolvimento de controles por seleção é menos provável.

Sidman (1989) sugere que, em uma situação de reforço negativo, os eventos que evitam o contato com os estímulos aversivos passariam a assumir uma função reforçadora positiva e, também, a controlar discriminativamente a resposta. Da mesma maneira, sugere que o estímulo correlacionado à produção do evento aversivo assumiria função discriminativa do controle da redução da resposta. Porém, como apontado por Lerman e Vorndran (2002), a pesquisa básica e aplicada sobre os efeitos do uso de contingências aversivas tem recebido pouca atenção, apesar de ainda haver certo desconhecimento sobre o tema. 
Os resultados dos testes de formação de classes de equivalência, a partir de uma contingência de reforço negativo do Experimento I, demonstram, em humanos e utilizando um aversivo condicionado (perda de pontos), o que foi sugerido por Sidman (1989) sobre a aquisição de controle discriminativo pelo estímulo correlacionado à retirada do aversivo, produzindo um controle por seleção. Adicionalmente, os resultados do Experimento II sugerem que o desenvolvimento de controle por seleção em uma contingência de reforço negativo é menos provável quanto maior o número de nódulos das classes a serem formadas.

Duas hipótese podem ser levantadas sobre o tipo de controle estabelecido pelo estímulo correlacionado à produção de um evento aversivo $\left(\mathrm{S}^{\mathrm{Dp}}\right)$. A primeira sugere que, da mesma maneira que um $\mathrm{S}^{\mathrm{Dp}}$ pode controlar a redução da resposta (função inibitória condicionada), pode controlar a ocorrência do responder no elemento que evita a produção do punidor, produzindo um responder típico de rejeição. Porém, este desempenho não foi observado no Experimento II em função de características do procedimento que impediriam o $S^{D p}$ de assumir controle da resposta.

Doughty et al. (2007), em uma revisão sobre as demonstrações de controle de estímulos pelo evento correlacionado à punição (controle por $\mathrm{S}^{\mathrm{Dp}}$ ), sugerem que apesar desse tipo de controle ser demonstrado em não-humanos (e.g. Honig \& Slivka’s, 1964, demonstração de um gradiente de inibição), as pesquisas com participantes humanos têm dificuldade em diferenciar quando o controle se dá pelo evento correlacionado ao estímulo aversivo em si $\left(S^{\mathrm{p}}\right)$ ou pelo $\mathrm{S}^{\mathrm{Dp}}$ (e.g. O’Donnell \& Crosbie, 1998; O’Donnell, Crosbie, Williams, \& Saunders, 2000).

Ao considerar quais as variáveis relevantes na produção do controle por $\mathrm{S}^{\mathrm{Dp}}$, Doughty et al. (2007) apontam que esse tipo de controle não se estabelece em 
procedimentos nos quais as consequências punidoras são apresentadas imediatamente após a escolha do elemento incorreto, e a demonstração de redução da probabilidade da resposta apenas acontece após a primeira ocorrência do $S^{p}$ (e.g. O’Donnell, Crosbie, Williams, \& Saunders, 2000). Doughty et al. sugerem que, durante o período de treino das discriminações, a apresentação quase simultânea do $S^{\mathrm{Dp}}$ e do $\mathrm{S}^{\mathrm{p}}$ (estímulo aversivo previamente à manipulação experimental) sombrearia o estímulo correlacionado, impedindo que ele adquirisse controle.

Vale sublinhar que, nos Experimentos I e II, o procedimento empregado para as tentativas da condição de reforço negativo (punição para escolha incorreta) é similar ao apontado por Doughty et al. (2007) como responsável pela não produção, ou menor probabilidade, de controle de estímulos por parte do evento correlacionado à punição. Ou seja, nos procedimentos empregados no presente trabalho, a punição por escolher é apresentada imediatamente após a escolha do estímulo incorreto (FR1 com atraso zero), o que poderia, assim como nos procedimentos de O’Donnell e Crosbie (1998) e O’Donnell et al. (2000), ser responsável pela falta de controle por parte dos estímulos correlacionados aos eventos aversivos e, consequentemente, pela produção de um desempenho por rejeição, ao menos em uma situação com classes maiores (Experimento II).

A segunda hipótese baseia-se nos dados a respeito do efeito da punição sobre a escolha (e.g. Critchfield, et al., 2003; de Villiers, 1980; Deluty, 1976; Farley, 1980). Conforme abordado na introdução, dois modelos são propostos para descrever o efeito da punição na alocação da resposta em uma situação de escolha. O primeiro é o modelo aditivo (Deluty, 1976), o qual assume que o efeito da punição em uma escolha adiciona valor ao elemento concorrente; o segundo é o modelo subtrativo (e.g. de Villiers, 1980), 
segundo o qual o efeito da punição em uma das escolhas é apenas subtrair valor da escolha correlacionada à punição.

De acordo com as pesquisas que contrapuseram estes dois modelos, o modelo que melhor descreve os efeitos da punição no controle do responder é o subtrativo, tanto em uma situação de escolha concorrente (e.g. Critchfield, et al., 2003) quanto em uma situação de detecção de sinais ou discriminação condicional (e.g. Lie \& Alsop, 2009).

Assim, essa hipótese supõe que a punição "enfraquece" o controle de estímulos, tornando-o menos provável. Isso produziria os resultados obtidos no Experimento II, no qual foi observada grande variabilidade e um resultado inconsistente com o padrão típico de controle por rejeição nos testes de formação de classes de equivalência.

É importante ressaltar que nenhuma das hipóteses levantadas explica os dados obtidos no Experimento I, porém, assim como no debate sobre "o que conta como bom" na avaliação do impacto diferencial do reforço e da punição, muito provavelmente estamos lidando com dois processos que ocorrem simultaneamente. $\mathrm{O}$ da aquisição de controle por parte do evento correlacionado à retirada do evento aversivo e a aquisição de controle por parte do próprio evento aversivo.

Experimentos futuros poderiam testar as hipóteses levantadas verificando se o uso de uma consequência aversiva atrasada produziria um padrão típico de controle por rejeição. Ademais, poderiam avaliar mais separadamente qual os padrões de controle de estímulos produzido por contingências aversivas. 


\section{CONCLUSÕES}

Os dados obtidos no Experimento I e II sugerem que é possível a formação de classes de equivalência a partir de uma contingência de reforço negativo, e que a probabilidade de formação de classes de equivalência é menor quando utilizada uma contingência de reforço negativo

Adicionalmente, os dados da aquisição das discriminações condicionais corroboram a hipótese do impacto diferencial, na qual a punição (perda de pontos) desloca a probabilidade do responder em direção ao evento que não produz a punição mais do que o reforço atrai. Contudo, foi discutida a necessidade de investigar as fontes de variabilidade individual, como por exemplo, o grau de aversividade dos estímulos ou procedimentos que permitam uma avaliação mais adequada dos diferentes efeitos.

Consideramos que a formulação sobre o que compõe as classes de equivalência, apresentada por Sidman (2000), é pouco descritiva e mostrou-se mais produtivo avaliar quais controles de estímulos foram produzidos a partir de cada contingência de reforço. Como consequência desta decisão, houve a necessidade de uma formulação que descrevesse mais precisamente como os eventos no ambiente podem passar a controlar o responder. Esta necessidade se faz ainda mais evidente no que diz respeito aos controles de estímulos produzidos a partir de contingências que envolvem o uso de eventos aversivos. Consequentemente, pudemos observar que uma formulação sobre como os estímulos se tornam substituíveis entre si no controle do responder será sempre precária, sem uma formulação de como os estímulos controlam o responder. 


\section{REFERÊNCIAS}

Arntzen, E., Grondahl, T., \& Eilifsen, C. (2010). The effects of different training structures in the establishment of conditional discriminations and the subsequent performance on the tests for stimulus equivalence. The Psychological Record, 60, 437-462.

Arntzen, E., \& Holth, P. (1997). Probability of stimulus equivalence as a function of training design. The Psychological Record, 47, 309-320.

Arntzen, E., \& Holth, P. (2000a). Differential probabilities of equivalence outcome in individual subjects as a function of training structure. The Psychological Record, 50, 603-628.

Arntzen, E., \& Holth, P. (2000b). Probability of stimulus equivalence as a function of class size vs. number of classes. The Psychological Record, 50, 79-104.

Balsam, P. D., \& Bondy, A. S. (1983). The negative side effects of reward. Journal of Applied Behavior Analysis, 16, 283-296.

Barnes -Holmes , D., Hayden, E., Barnes -Holmes , Y., \& Stewart , I. (2008). The Implicit Relational Assessment Procedure (IRAP) as a response-time and eventrelated-potentials methodology for testing natural verbal relations: A Preliminary Study. The Psychological Record, 58, 497-516

Barros, R. S., Galvão, O. F., \& McIlvane, W. J. (2002). Generalized identity matchingto-sample in Cebus apella. Psychological Record, 52, 441-460.

Barros, R. S., Galvão, O. F., \& McIlvane, W. J. (2003). The search for relational learning capacity in Cebus apella: A programmed educational approach. In S. Soraci Jr. \& K. Murata-Soraci (Eds). Visual information processing, (pp. 223245). Connecticut, MA: Praeger. 
Barros, R. S., Galvão, O. F., Brino, A. L. F., Goulart, P. R. K., \& McIlvane, W. J. (2005). Variáveis de procedimento na pesquisa sobre classes de equivalência: Contribuições para o estudo do comportamento simbólico. Revista Brasileira de Análise do Comportamento, 1, 15-27.

Barros, R. S., Lionello-DeNolf, K. M., Dube, W. V., \& McIlvane, W. J. (2006). A formação de classes de equivalência via pareamento por identidade e discriminação simples com consequências específicas para as classes. Revista Brasileira de Análise do Comportamento, 2, 79-92

Baum, W. M. (1974). On two types of deviation from the matching law: Bias and undermatching. Journal of the Experimental Analysis of Behavior, 22, 231-242.

Baumeister, R. F., Bratslavsky, E., Finkenauer, C., \& Vohs, K. D. (2001). Bad is stronger than good. Review of General Psychology, 5, 323-370

Bradshaw, C., Szabadi, E., \& Bevan, P. (1979). The effect of punishment on freeoperant choice behavior in humans. Journal of the Experimental Analysis of Behavior, 31, 71-81

Buffington, D. M., Fields, L., \& Adams, B. J. (1997). Enhancing the formation of equivalence classes by pretraining of other equivalence classes. The Psychological Record, 47, 1-20.

Catania, A. C. (1998): Learning, 4. utg. Englewood Cliffs: Prentice-Hall

Clayton, M. C., \& Hayes, L. J. (1999). Conceptual differences in the analysis of stimulus equivalence. The Psychological Record, 49, 145-161. 
Cumming, W. W., \& Berryman, R. (1965). The complex discriminated operant: studies of matching-to-sample and related problems. In D. J. Mostofsky (Org.), Stimulus generalization (pp. 284-330). Standford, CA: Standford University Press.

Critchfield, T. S., \& Magoon, M. A. (2001). On the differential impact of positive and negative reinforcement. Experimental Analysis of Human Behavior Bulletin, 19, $16-18$.

Critchfield, T. S., Paletz, E. M., MacAleese, K. R., \& Newland, M. C. (2003). Punishment in human choice: Direct or competitive suppression? Journal of the Experimental Analysis of Behavior, 80, 1-27.

Davison, M., \& Nevin, J. A. (1999). Stimuli, reinforcers, and behavior: An integration. Journal of the Experimental Analysis of Behavior, 71, 439-482.

Davison, M., \& Tustin, R. (1978). The relation between the generalized matching law and signal-detection theory. Journal of the Experimental Analysis of Behavior, 29, $331-336$.

Davison, M., \& McCarthy, D. (1988). The matching law: A research review. Hillsdale, NJ: Erlbaum.

D’Amato, M. R., Salmon, D. P., Loukas, E., \& Tomie, A. (1985). Symmetry and transitivity of conditional relations in monkeys ( Cebus apella ) and pigeons (Columba livia ). Journal of Experimental Analysis of Behavior , 44, 35-47.

Deacon, T. W. (1997). The Symbol ic Species: The Co-evolution of Language and the Brain. New York: Norton. 
Deluty, M. Z. (1976). Choice and the rate of punishment in concurrent schedules. Journal of the Experimental Analysis of Behavior, 25, 75-80.

Delgado, D., \& Hayes, L. J. (2014). An Integrative Approach to Learning Processes: Revisiting Substitution of Functions. The Psychological Record, 64, 625-637.

de Rose, J. C., Kato, O. M., Thé, A. P. G., \& Kledaras, J. B. (1997). Variáveis que afetam a formação de classes de estímulos: Estudos sobre efeitos do arranjo de treino. Acta Comportamentalia, 5, 143-163.

de Rose, J. C. C., de Souza, D. G., Rossito, A. L. \& de Rose, T. M. S. (1989). Aquisição de leitura após história de fracasso escolar. Psicologia: Teoria e Pesquisa, 5, 325346.

Devany, J. M., Hayes, S. C., Nelson, R. O. (1986). Equivalence class formation in language-able and language-disabled children. Journal of the Experimental Analysis of Behavior, 46, 243-257.

de Villiers, P. A. (1980). Toward a quantitative theory of punishment. Journal of the Experimental Analysis of Behavior, 33, 15-25.

Dickins, T. E. and Dickins, D. W. (2001) Symbols, Stimulus Equivalence and the Origins of Language. Behavior and Philosophy, 29: 221 - 244.

Dinsmoor, J. (1954). Punishment I: The avoidance hypothesis. Psychological Review, $61,34-46$.

Dinsmoor, J. A. (1995). Stimulus control: Part I. The Behavior Analyst, 18, 51-68. 
Dinsmoor, J. A. (2001). Still no evidence for temporally extended shock-frequency reduction as a reinforcer. Journal of the Experimental Analysis of Behavior, 75, $367-378$.

Dymond, S., \& Rehfeldt, R. A. (2001). Supplemental measures of derived stimulus relations. Experimental Analysis of Human Behavior Bulletin, 19, 8-12.

Doughty, A. H., Doughty, S. S., O’Donnell, J., Saunders, K. J., \& Williams, D. C. (2007). Stimulus control of punishment effects: Determining the controlling variables. Mexican Journal of Behavior Analysis. 33, 57-66.

Dube, W. V., \& McIlvane, W. J. (1995). Stimulus-reinforcer relations and emergent matching to sample. Psychological Record, 45, 591-612.

Dube, W.V. \& McIlvane, W.J. (1996). Some implications of a stimulus control topography analysis for emergent behavior and stimulus classes. In T. R. Zentall \& P.M. Smeets (Eds.), Stimulus class formation in humans and animals: Advances in Psychology. NL: Elsevier.

Dube, W.V., McIlvane, W.J., Mackay, H.A., \& Stoddard, L.T. (1987). Stimulus class membership established via stimulus-reinforcer relations. Journal of the Experimental Analysis of Behavior, 47, 159-175.

Dube, W.V., McIlvane, W.J., Maguire, R.W., Mackay, H.A., \& Stooddard, L.T. (1989). Stimulus class formation and stimulus-reinforcers relations. Journal of the Experimental Analysis of Behavior, 51, 65-76.

Dugdale, N. \& Lowe, C.F. (2000). Testing for symmetry in the conditional discriminations of language trained chimpanzees. Journal of the Experimental Analysis of Behavior, 73, 5-22. 
Edwards, C. A., Jagielo, J. A., Zentall, T. R., \& Hogan, D. E. (1982). Acquired eqivalence and distinctiveness in matching to sample by pigeons: Mediation by reinforcer-specific expectancies. Journal of Experimental Psychology: Animal Behavior Processes, 8, 244-259.

Estevez, A. F., Fuentes , L. J., Mari-Beffa , P., Gonzalez, C., \& Alvarez, D. (2001). The differential outcome effect as a useful tool to improve conditional discrimination learning in children. Learning and Motivation, 32, 48-64.

Farley, J., \& Fantino, E. (1978). The symmetrical law of effect and the matching relation in choice behavior. Journal of the Experimental Analysis of Behavior, 29, $37-60$.

Fields, L., \& Verhave, T. (1987). The structure of equivalence classes. Journal of the Experimental Analysis of Behavior, 48, 317-332. doi: 10.1901/jeab.1987.48-317

Fields, L., Adams, B. J. \& Verhave, T. (1993). The effects of equivalence class structure on test performances. The Psychological Record, 43(4), 697-715.

Frank, A. J. \& Wasserman, E. A. (2005). Associative symmetry in the pigeon after successive matching-to-sample training. Journal of the Experimental Analysis of Behavior, 84, 147- 165.

Estévez, A.F., Overmier, J.B., \& Fuentes, L.J. (2003). Differential outcomes effect in children: Demonstration and mechanisms. Learning and Motivation, 34, 148-167

Green, G., \& Saunders, R. R. (1998). Stimulus equivalence. In K. A. Lattal, \& M. Perone (Eds.). Handbook of research methods in human operant behavior (pp. 229-262). New York: Plenum. 
Goeters , S., Blakely, E., \& Poling, A. (1992). The differential outcomes effect. The Psychological Record, 42, 389-411.

Hackenberg, T. D. (2009). Token reinforcement: A review and analysis. Journal of the Experimental Analysis of Behavior, 91, 257-286.

Hamasaki, E. I. M. (2009). Respostas de observação na tarefa de pareamento ao modelo: Analisando topografias de controle de estímulos e seus efeitos sobre a formação de equivalência. Tese de doutorado, Universidade de São Paulo, São Paulo.

Hamasaki, E. I. de M. ; Tomanari, G. Y. (2009). Efeitos de diferentes contingências sobre o uso de tempos verbais na construção de frases. Revista Brasileira de Terapia Comportamental e Cognitiva, 11, 119-131.

Hayes, L. J. (1992). Equivalence as process. In S. C. Hayes \& L. J. Hayes (Eds.), Understanding verbal relations. Reno, NV: Context Press.

Hayes, S. C., Barnes-Holmes, D., \& Roche, B. (Eds.). (2001). Relational Frame Theory: A Post-Skinnerian account of human language and cognition. New York: Plenum Press.

Herrnstein, R. J., \& Hineline, P. N. (1966). Negative reinforcement as shock-frequency reduction. Journal of the Experimental Analysis of Behavior, 9, 421-430.

Herrnstein, R. J. (1970). On the law of effect. Journal of the Experimental Analysis of Behavior, 13, 243-266.

Hineline, P. N. (1984). Aversive control: A separate domain? Journal of the Experimental Analysis of Behavior, 42, 495-509. 
Honig, W. K., \& Slivka, R. M. (1964). Stimulus generalization of the effects of punishment. Journal of the Experimental Analysis of Behavior, 7, 21-25.

Horne, P.J. \& Lowe, C.F. (1996). On the origins of naming and other symbolic behavior. Journal of the Experimental Analysis of Behavior, 65, 185-241.

Hunziker, M. H. L. (2011) Afinal, o que é controle aversivo? Acta Comportamentalia: Revista Latina de Análisis de Comportamiento, 19, 9-19.

Kahneman, D., \& Tversky, A. (1979). Prospect theory: An analysis of decision under risk. Econometrica, 47, 263-291

Kastak, C. R., Schusterman, R. J., \& Kastak, D. (2001). Equivalence classification by California sea lions using class-specific reinforcers. Journal of the Experimental Analysis of Behavior, 76, 131-158.

Lie, C., \& Alsop, B. (2007). Reinforcement and punishment in behavioral models of signal detection. Mexican Journal of Behavior Analysis, 33, 45-55.

Lie, C., \& Alsop, B. (2009). Effects of point-loss punishers on human signal-detection performance. Journal of the Experimental Analysis of Behavior, 92, 17-39.

Lie, C., \& Alsop, B. (2010). Stimulus disparity and punisher control of human signaldetection performance. Journal of the Experimental Analysis of Behavior, 93, 185-201.

Leader, G., Barnes, D., \& Smeets, P. M. (1996). Establishing equivalence relations using a respondent-type training procedure. The Psychological Record, 46, 685706. 
Leader, G., Barnes-Holmes, D., \& Smeets, P. M. (2000). Establishing equivalence relations using a respondent type training procedure III. The Psychological Record, 50, 63-78.

Lerman, D. C., \& Vorndran, C. M. (2002). On the status of knowledge for using punishment: Implications for treating behavior disorders. Journal of Applied Behavior Analysis, 35, 431-464.

Maki, P., Overmier, J. B., Delos , S., \& Gutmann, A. J. (1995). Expectancies as factors influencing conditional discrimination performance of children. The Psychological Record, 45, 45-71.

Magnusson, A. (2002). Topography of eye movements under select and reject control. Dissertação de mestrado, Shriver Center, Northeastern University, Boston

Magoon, M. A., \& Critchfield, T. S. (2008). Concurrent schedules of positive and negative reinforcement: Differential-impact and differential-outcomes hypotheses. Journal of the Experimental Analysis of Behavior, 90, 1-22.

Manabe, K., Kawashima, T., \& Staddon, J. E. R. (1995). Differential vocalization in budgerigars: Towards an experimental analysis of naming. Journal of the Experimental Analysis of Behavior, 63, 111-126.

McIlvane, W.J., Dube, W.V., Kledaras, J.B., de Rose, J.C., \& Stoddard, L.T., (1992). Stimulus-reinforcer relations and conditional discriminations. Em Hayes, S.C., \& Hayes, L.J. (Eds.) Understanding verbal relations. Reno, Nevada: Context Press.

McIlvane, W. J., Serna, R. W., Dube, W. V., \& Stromer, R. (2000). Stimulus control topography coherence and stimulus equivalence: Reconciling test outcomes with 
theory. In J. Leslie \& D. E. Blackman (Eds.), Experimental and applied analysis of human behavior (pp. 85-110). Reno, NV: Context Press.

McIlvane, W. J., \& Dube, W. V. (2003). Stimulus control topography coherence theory: Foundations and extensions. The Behavior Analyst, 26, 195-213.

Miller, Odette T.; Waugh, Kevin M.; and Chambers, Karen (2002) "Differential Outcomes Effect: Increased Accuracy in Adults Learning Kanji with Stimulus Specific Rewards. The Psychological Record, 51, 315-323

Miyashita , Y., Nakajima, S., \& Imada , H. (2000). Differential outcome effect in the horse. Journal of the Experimental Analysis of Behavior, 74, 245-253.

Minster, S,T., Jones, B.M., Elliffe, D., \& Muthukumaraswamy, S.D. (2006). Stimulus equivalence: Testing Sidman's (2000) theory. Journal of the Experimental Analysis of Behavior, 85, 371-391.

Minster, S.T., Elliffe, D., \& Muthukumaraswamy, S.D. (2011). Emergent stimulus relations depend on stimulus correlation and not on reinforcement contingencies. Journal of the Experimental Analysis of Behavior. 95, 327-342

Motoulsky, H., \& Christopoulis, A. (2006). Fitting models to biological data using linear and nonlinear regression: A practical guide to curve fitting. San Diego: GraphPad Software.

Nevin, J. A., Ward, R. D., Jimenez-Gomez, C., Odum, A. L., \& Shahan, T. A. (2009). Differential outcomes enhance accuracy of delayed matching to sample but not resistance to change. Journal of Experimental Psychology: Animal Behavior Processes, 32, 74-91. 
O’Donnell, J. (2001). The discriminative stimulus for punishment or $\mathrm{S}^{\mathrm{Dp}}$. The Behavior Analyst, 24, 261-262.

O’Donnell, J., \& Crosbie, J. (1998). Punishment generalization gradients with humans. The Psychological Record, 48, 211232.

O’Donnell, J., Crosbie, J., Williams, D. C., \& Saunders, K. J. (2000). Stimulus control and generalization of pointloss punishment with humans. Journal of the Experimental Analysis of Behavior, 73, 261-274.

Overmier, J. B., Bull, J., A., \& Trapold, M. A. (1971). Discriminative cue properties of different fears and their role in response selection in dogs. Journal of Comparative and Physiological Psychology, 76, 478-482.

Pelick, K. (2005). Equivalence class expansion via class-specific reinforcement in children with autism. Wilmington, North Carolina.

Perez, W. F. (2008). Movimentos dos olhos e topografias de controle de estímulos em treino de discriminação condicional e testes de equivalência. Dissertação de mestrado, Programa de Pós-graduação Psicologia Experimental, Universidade de São Paulo, São Paulo

Perez, W. F., \& Tomanari, G. Y. (2008). Controles por seleção e rejeição em treinos de discriminação condicional e testes de equivalência. Revista Brasileira de Análise do Comportamento, 4, 175-190.

Perez, W. F., \& Tomanari, G. Y. (2013). Inferindo a ocorrência dos controles por seleção e por rejeição em tarefas de emparelhamento com o modelo: uma revisão metodológica. Acta comportamentalia, 21, 211-225. 
Peterson, G. B., \& Trapold, M. A. (1980). Effects of altering outcome expectancies on pigeons' delayed conditional discrimination performance. Learning \& Motivation, $11,267-288$.

Peterson, G. B., Wheeler, R. L., \& Trapold, M. A. (1980). Enhancement of pigeons' conditional discrimination performances by expectancies of reinforcement and nonreinforcement. Animal Learning \& Behavior, 8, 22-30.

Rasmussen, E. B., \& Newland, M. C. (2008). Asymmetry of reinforcement and punishment in human choice. Journal of the Experimental Analysis of Behavior, $89,157-167$.

Ray, B. A., \& Sidman, M. (1970). Reinforcement schedules and stimulus control. In W. N. Schoenfeld (Ed.), The theory of reinforcement schedules (pp. 187-214). New York: Appleton- Century-Crofts.

Santi, A., \& Roberts, W. A. (1985). Prospective representation: The effects of varied mapping of sample stimuli to comparison stimuli and differential trial outcomes on pigeons' working memory. Animal Learning \& Behavior, 13, 103-108.

Saunders, R. R., \& Green, G. (1992). The nonequivalence of behavioral and mathematical equivalence. Journal of the Experimental Analysis of Behavior, 57, 227-241.

Saunders, R. R., \& Green, G. (1999). A discrimination analysis of training structure effects on stimulus equivalence outcomes. Journal of the Experimental Analysis of Behavior, 72, 117-137. doi: 10.1901/jeab.1999.72-117 
Saunders, K. J., \& Spradlin, J. E. (1989). Conditional discrimination in mentally retarded adults: the effect of training the component simple discriminations. Journal of the Experimental Analysis of Behavior, 52, 1-12.

Schmidtke, K. A (2009). The diferential outcome effect with tipical adult humans. Doctorate`s disertation. Graduate faculty of Auburn University. Auburn/Alabama.

Schusterman RJ, Kastak D. A. (1993). California sea lion (zalophus californianus) is capable of forming equivalence relations. The Psychological Record, 43, 823839.

Schuster, R., \& Rachlin, H. (1968). Indifference between punishment and free shock: Evidence for the negative law of effect. Journal of the Experimental Analysis of Behavior, 11, 777-786.

Schenk, J.J. (1994). Emergent relations of equivalence generated by outcome-specific consequences in conditional discrimination. The Psychological Record, 44, 537558.

Sidman, M. (2000). Equivalence relations and the reinforcement contingency. Journal of the Experimental Analysis of Behavior, 74, 127-146.

Sidman, M. (1994). Equivalence relations and behavior: A research story. Boston, MA: Authors Cooperative.

Sidman, M. (1989). Coercion and its fallout. Boston: Authors Cooperative.

Sidman, M., \& Tailby, W. (1982). Conditional discrimination vs. matching-to-sample: An expansion of the testing paradigm. Journal of the Experimental Analysis of Behavior, 37, 5-22. 
Sidman, M., Rauzin, R., Lazar, R., Cunningham, S., Tailby, W., \& Carrigan, P. (1982). A search for symmetry in the conditional discriminations of rhesus monkeys, baboons, and children. Journal of the Experimental Analysis of Behavior, 37, 2344.

Sidman, M., Kirk, B. e Willson-Morris, M. (1985). Six-member stimulus classes generated by conditional discrimination procedures. Journal of the Experimental Analysis of Behavior, 43, 21-42.

Smeets, P. M., Leader, G., \& Barnes, D. (1997). Establishing stimulus classes in adults and children using a respondent-type training procedure: A follow-up study. The Psychological Record, 47, 285-308.

Skinner, B. F. (1950). Are theories of learning necessary? Psychological Review, 57, 193-216.

Skinner, B. F. (1953). Science and human behavior. New York: Free Press.

Skinner, B. F. (1957). Verbal behavior. Acton: Copley Publishing.

Skinner, B. F. (1969). Contingencies of reinforcement: a theoretical analysis. Nova York: Appleton-Century-Crofts.

Taylor, S. E. (1991). Asymmetrical effects of positive and negative events: The mobilization-minimization hypothesis. Psychological Bulletin, 110, 67-85.

Terrace, H. (1966). Stimulus control. In W. K. Honig (Ed.), Operant behavior: Areas of research and application (pp. 271-344). New York: Meredith.

Tonneau, F. (2001). Equivalence relations: A critical analysis. European Journal of Behavior Analysis, 2, 1-128. 
Trapold, M. A. (1970). Are expectancies based upon different positive reinforcing events discriminably different? Learning and Motivation, 1, 129-140.

Urcuioli, P. J. (1991). Retardation and facilitation of matching acquisition by differential outcomes. Animal Learning \& Behavior, 19, 29-36.

Urcuioli, P. J. (1990). Some relationships between outcome expectancies and sample stimuli in pigeons' delayed matching. Animal Learning \& Behavior, 18, 302-314.

Urcuioli, P. J. (2005). Behavioral and associative effects of differential outcomes in discrimination learning. Learning \& Behavior, 33, 1-21.

Urcuioli, P. J. (2008). Associative symmetry, 'anti-symmetry', and a theory of pigeons' equivalence-class formation. Journal of the Experimental Analysis of Behavior, 90, 257-282.

Vasconcelo, M. \& Urcuiolli, P. J. (2011). Associative symmetry in a spatial sampleresponse paradigm. Behavioral Processes, 86, 305-315.

Vaughan, W. (1988). Formation of equivalence sets in pigeons. Journal of the Experimental Psychology: Animal Behavior Processes , 14, 36-42.

Velasco, S. M., Huziwara, E. M., Machado, A., \& Tomanari, G. Y. (2010). Associative Symmetry by Pigeons after Few-Exemplar Training. Journal of the Experimental Analysis of Behavior, 94, 283-295. 


\section{ANEXO I}

\section{TERMO DE CONSENTIMENTO LIVRE E ESCLARECIDO}

Você está sendo convidado (a) a participar, como voluntário, de uma pesquisa em Análise Experimental do Comportamento sob o título de "Efeito de diferentes contingências de reforço no estabelecimento de discriminações condicionais e formação de classes de estímulos equivalentes", conduzida no Instituto de Psicologia da Universidade de São Paulo por Paulo Sérgio Dillon Soares Filho, sob a orientação de Gerson Yukio Tomanari. A seguir serão descritas as principais características desta pesquisa. Tendo sido devidamente esclarecido em seus mínimos detalhes, ciente dos serviços e procedimentos aos quais será submetido, não restando quaisquer dúvidas a respeito do lido e explicado, caso você tenha interesse em participar, favor assinar as duas vias desse documento. Uma delas é sua e a outra é do pesquisador responsável.

\section{INFORMAÇÕES SOBRE A PESQUIISA}

O objetivo deste estudo é avaliar o efeito de diferentes contingências de reforço e do uso de consequências diferenciais (DOE) no estabelecimento de discriminações condicionais e na formação de classes de equivalência em participantes humanos

Você participará, individualmente, de uma tarefa na qual terá que escolher (clicar com o mouse sobre) estímulos que aparecerão na tela de um computador; sua participação será realizada em até três sessões com duração entre 40 e 50 minutos, cada. Sua participação é voluntária e você poderá interrompê-la a qualquer momento, sem nenhuma penalização ou prejuízo em relação ao pesquisador ou à instituição. Os dados obtidos nesta investigação serão utilizados para fins de pesquisa científica, desta ou de outras pesquisas relacionadas.

A qualquer momento durante sua participação, o pesquisador responsável poderá esclarecer dúvidas referentes ao estudo. Qualquer dúvida após sua participação, por favor, entrar em contato com o pesquisador responsável por meio das seguintes formas de contato - telefone: (11)30911903; e-mail: paulodillon@gmail.com, ou com o Comitê de Ética em Pesquisa envolvendo Seres Humanos do Instituto de Psicologia / USP através dos contatos: 1130914182 - E-mail: ceph.ip@usp.br.

Informações adicionais: $O$ procedimento não envolve medidas de inteligência ou de aspectos afetivos ou emocionais. A pesquisa não oferece riscos evidentes que possam causar dano à sua integridade física, psíquica ou social. Qualquer desconforto ou cansaço relacionado ao tempo de participação na tarefa pode ser relatado e a sua participação interrompida imediatamente sem nenhuma penalização ou prejuízo. Os resultados deste estudo não trazem benefícios diretos ao participante. As informações obtidas poderão ser relevantes para o aprimoramento e desenvolvimento de estudos acerca desta temática. Você poderá ser ressarcido de possíveis despesas com sua participação nesta pesquisa.

Condições de Sigilo: Em nenhuma hipótese você será identificado quando o material for utilizado para propósitos de publicação científica ou educativa, garantindo assim a confidencialidade dos dados fornecidos, sua privacidade e o sigilo sobre as informações coletadas.

Ao assinar este termo de consentimento você estará autorizando sua participação como participante externo na presente pesquisa, podendo retirar o seu consentimento a qualquer momento. Sua recusa não trará nenhum prejuízo em sua relação com a pesquisa ou com ao pesquisador.

$\mathrm{Eu}$, declaro que, após convenientemente esclarecido(a) pelo pesquisador e ter entendido o que me foi explicado, consinto em participar do presente Projeto de Pesquisa. Confirmo que recebi uma cópia deste formulário de consentimento e que compreendo que sou livre para retirar-me do estudo em qualquer momento, sem qualquer penalidade. Dou meu consentimento de livre e espontânea vontade e sem reservas para participar deste estudo. 
São Paulo, de 2014

Assinatura do pesquisador:

Assinatura do participante da pesquisa:

Pesquisador responsável: Paulo Sérgio Dillon Soares Filho.

Endereço do pesquisador: Av. Prof. Mello de Moraes, 1721, Bloco A, Sala A-5, Cidade Universitária São Paulo - SP. Fone: (11) 3091-1903. E-mail: paulodillon@gmail.com, Endereço do CHEP-IPUSP: Av.

Professor Mello Moraes, 1721 - Bloco G, $2^{\circ}$ andar, sala 27, CEP 05508-030 - Cidade Universitária - São Paulo/SP. (11) 3091-4182. E-mail: ceph.ip@usp.br . 
ANEXO II
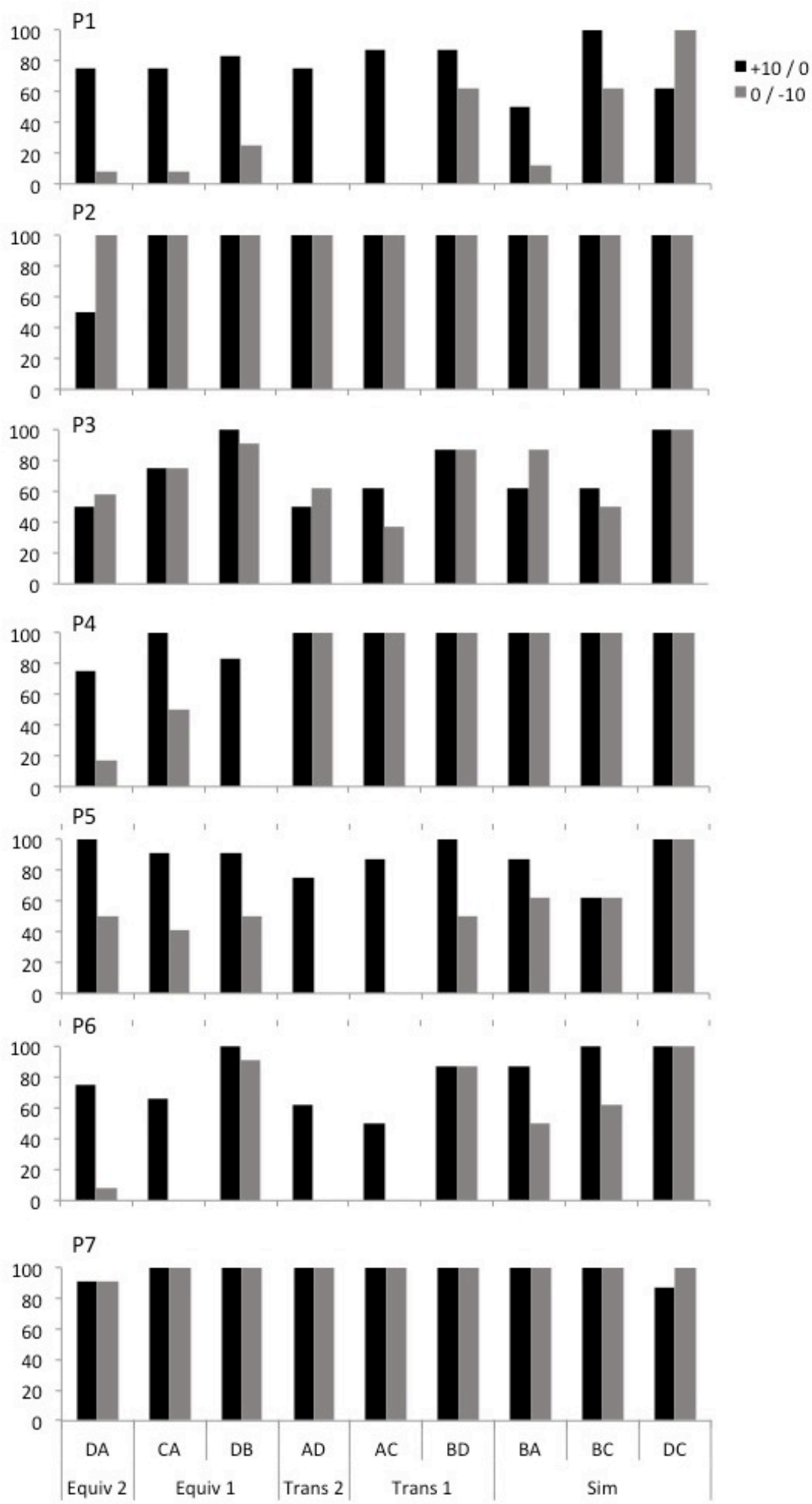

Figura 9. Porcentagem de acertos para cada tipo de teste de formação de classes de equivalência por participante. 
ANEXO III
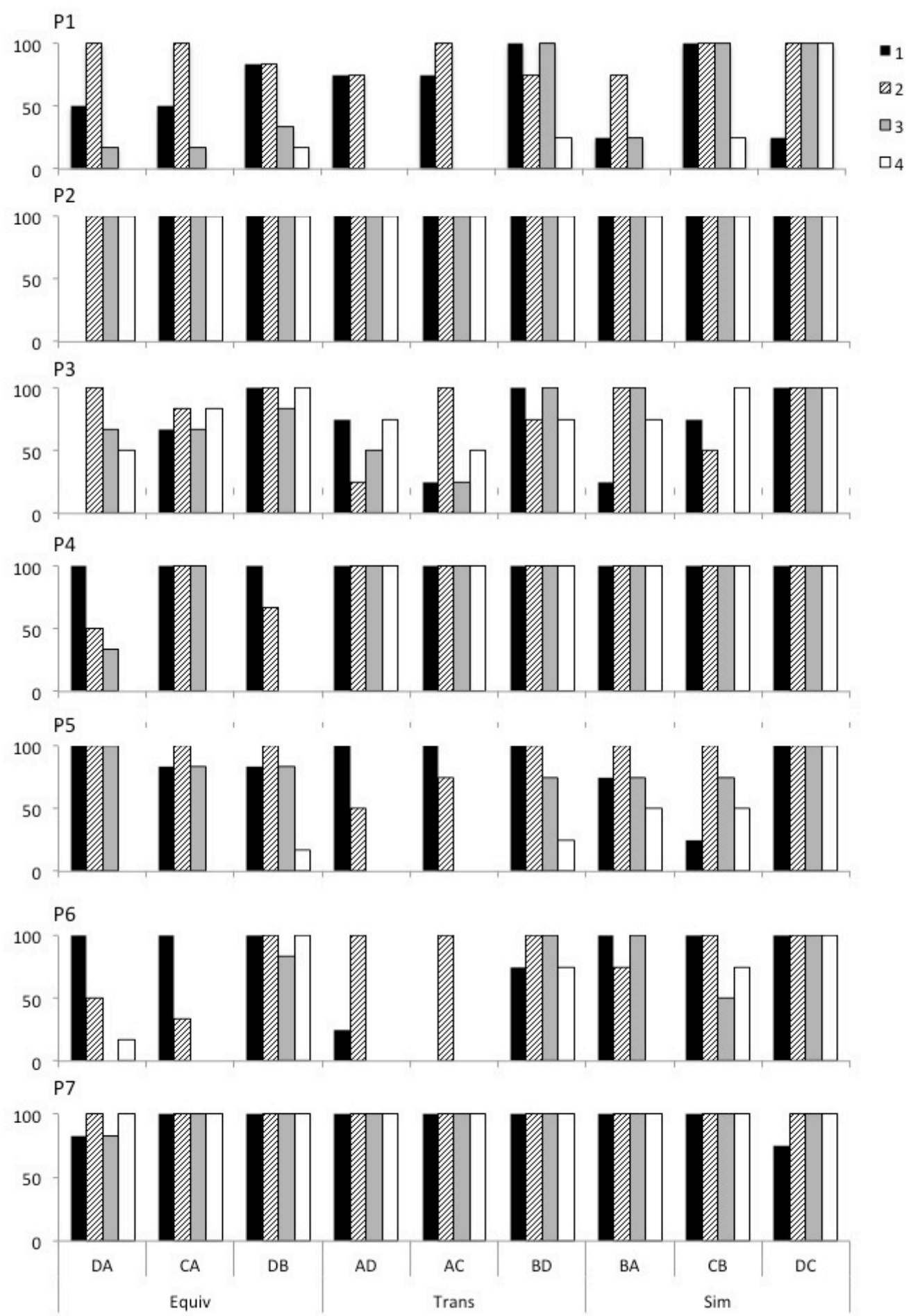

Figura 10. Porcentagem de acertos para cada relação condicional avaliada durante o teste de formação de classes de equivalência por participante. 